\title{
Management of spontaneous pneumothorax: British Thoracic Society pleural disease guideline 2010
}

\author{
Andrew MacDuff, ${ }^{1}$ Anthony Arnold, ${ }^{2}$ John Harvey, ${ }^{3}$ on behalf of the BTS Pleural \\ Disease Guideline Group
}

${ }^{1}$ Respiratory Medicine, Royal Infirmary of Edinburgh, UK ${ }^{2}$ Department of Respiratory Medicine, Castle Hill Hospital, Cottingham, East Yorkshire, UK ${ }^{3}$ North Bristol Lung Centre, Southmead Hospital, Bristol, UK

\section{Correspondence to}

Dr John Harvey, North Bristol Lung Centre, Southmead Hospital, Bristol BS10 5NB, UK: john.harvey@nbt.nhs.uk

Received 12 February 2010 Accepted 4 March 2010

\section{INTRODUCTION}

The term 'pneumothorax' was first coined by Itard and then Laennec in 1803 and 1819 respectively, ${ }^{1}$ and refers to air in the pleural cavity (ie, interspersed between the lung and the chest wall). At that time, most cases of pneumothorax were secondary to tuberculosis, although some were recognised as occurring in otherwise healthy patients ('pneumothorax simple'). This classification has endured subsequently, with the first modern description of pneumothorax occurring in healthy people (primary spontaneous pneumothorax, PSP) being that of Kjærgaard ${ }^{2}$ in 1932. It is a significant global health problem, with a reported incidence of $18-28 / 100000$ cases per annum for men and 1.2-6/100 000 for women. ${ }^{3}$

Secondary pneumothorax (SSP) is associated with underlying lung disease, in distinction to PSP, although tuberculosis is no longer the commonest underlying lung disease in the developed world. The consequences of a pneumothorax in patients with pre-existing lung disease are significantly greater, and the management is potentially more difficult. Combined hospital admission rates for PSP and SSP in the UK have been reported as 16.7/100000 for men and 5.8/100000 for women, with corresponding mortality rates of $1.26 /$ million and 0.62 / million per annum between 1991 and $1995 .{ }^{4}$

With regard to the aetiology of pneumothorax, anatomical abnormalities have been demonstrated, even in the absence of overt underlying lung disease. Subpleural blebs and bullae are found at the lung apices at thoracoscopy and on CT scanning in up to $90 \%$ of cases of PSP, ${ }^{5}$ and are thought to play a role. More recent autofluorescence studies ${ }^{7}$ have revealed pleural porosities in adjacent areas that were invisible with white light. Small airways obstruction, mediated by an influx of inflammatory cells, often characterises pneumothorax and may become manifest in the smaller airways at an earlier stage with 'emphysema-like changes' (ELCs). ${ }^{8}$

Smoking has been implicated in this aetiological pathway, the smoking habit being associated with a $12 \%$ risk of developing pneumothorax in healthy smoking men compared with $0.1 \%$ in nonsmokers. ${ }^{9}$ Patients with PSP tend to be taller than control patients. ${ }^{10} 11$ The gradient of negative pleural pressure increases from the lung base to the apex, so that alveoli at the lung apex in tall individuals are subject to significantly greater distending pressure than those at the base of the lung, and the vectors in theory predispose to the development of apical subpleural blebs. ${ }^{12}$

Although it is to some extent counterintuitive, there is no evidence that a relationship exists between the onset of pneumothorax and physical activity, the onset being as likely to occur during sedentary activity. ${ }^{13}$

Despite the apparent relationship between smoking and pneumothorax, $80-86 \%$ of young patients continue to smoke after their first episode of PSP. ${ }^{14}$ The risk of recurrence of PSP is as high as $54 \%$ within the first 4 years, with isolated risk factors including smoking, height and age $>60$ years. ${ }^{12} 15$ Risk factors for recurrence of SSP include age, pulmonary fibrosis and emphysema. ${ }^{15} 16$ Thus, efforts should be directed at smoking cessation after the development of a pneumothorax.

The initial British Thoracic Society (BTS) guidelines for the treatment of pneumothoraces were published in $1993 .{ }^{17}$ Later studies suggested that compliance with these guidelines was improving but remained suboptimal at only $20-40 \%$ among non-respiratory and A\&E staff. Clinical guidelines have been shown to improve clinical practice, ${ }^{18}{ }^{19}$ compliance being related to the complexity of practical procedures ${ }^{20}$ and strengthened by the presence of an evidence base. ${ }^{21}$ The second version of the BTS guidelines was published in $2003^{22}$ and reinforced the trend towards safer and less invasive management strategies, together with detailed advice on a range of associated issues and conditions. It included algorithms for the management of PSP and SSP but excluded the management of trauma. This guideline seeks to consolidate and update the pneumothorax guidelines in the light of subsequent research and using the SIGN methodology. Traumatic pneumothorax is not covered by this guideline.

- SSP is associated with a higher morbidity and mortality than PSP. (D)

- Strong emphasis should be placed on smoking cessation to minimise the risk of recurrence. (D)

- Pneumothorax is not usually associated with physical exertion. (D)

\section{CLINICAL EVALUATION}

- Symptoms in PSP may be minimal or absent. In contrast, symptoms are greater in SSP, even if the pneumothorax is relatively small in size. (D)

- The presence of breathlessness influences the management strategy. (D)

- Severe symptoms and signs of respiratory distress suggest the presence of tension pneumothorax. (D)

The typical symptoms of chest pain and dyspnoea may be relatively minor or even absent, ${ }^{23}$ so that 
a high index of initial diagnostic suspicion is required. Many patients (especially those with PSP) therefore present several days after the onset of symptoms. ${ }^{24}$ The longer this period of time, the greater is the risk of re-expansion pulmonary oedema (RPO). ${ }^{25} 26$ In general, the clinical symptoms associated with SSP are more severe than those associated with PSP, and most patients with SSP experience breathlessness that is out of proportion to the size of the pneumothorax. ${ }^{27}$ These clinical manifestations are therefore unreliable indicators of the size of the pneumothorax. ${ }^{29} 30$ When severe symptoms are accompanied by signs of cardiorespiratory distress, tension pneumothorax must be considered.

The physical signs of a pneumothorax can be subtle but, characteristically, include reduced lung expansion, hyper-resonance and diminished breath sounds on the side of the pneumothorax. Added sounds such as 'clicking' can occasionally be audible at the cardiac apex. ${ }^{23}$ The presence of observable breathlessness has influenced subsequent management in previous guidelines. ${ }^{17} 23$ In association with these signs, cyanosis, sweating, severe tachypnoea, tachycardia and hypotension may indicate the presence of tension pneumothorax (see later section).

Arterial blood gas measurements are frequently abnormal in patients with pneumothorax, with the arterial oxygen tension $\left(\mathrm{PaO}_{2}\right)$ being $<10.9 \mathrm{kPa}$ in $75 \%$ of patients, ${ }^{31}$ but are not required if the oxygen saturations are adequate $(>92 \%)$ on breathing room air. The hypoxaemia is greater in cases of $\mathrm{SSP}^{31}$ the $\mathrm{PaO}_{2}$ being $<7.5 \mathrm{kPa}$, together with a degree of carbon dioxide retention in $16 \%$ of cases in a large series. ${ }^{32}$ Pulmonary function tests are poor predictors of the presence or size of a pneumothorax ${ }^{7}$ and, in any case, tests of forced expiration are generally best avoided in this situation.

The diagnosis of pneumothorax is usually confirmed by imaging techniques (see below) which may also yield information about the size of the pneumothorax, but clinical evaluation should probably be the main determinant of the management strategy as well as assisting the initial diagnosis.

\section{IMAGING \\ Initial diagnosis}

- Standard erect chest x-rays in inspiration are recommended for the initial diagnosis of pneumothorax, rather than expiratory films. (A)

- The widespread adoption of digital imaging (PACS) requires diagnostic caution and further studies since the presence of a small pneumothorax may not be immediately apparent. (D)

- CT scanning is recommended for uncertain or complex cases. (D)

The following numerous imaging modalities have been employed for the diagnosis and management of pneumothorax:

1. Standard erect PA chest x-ray.

2. Lateral x-rays.

3. Expiratory films.

4. Supine and lateral decubitus x-rays.

5. Ultrasound scanning.

6. Digital imaging.

7. CT scanning.

\section{Standard erect PA chest $\mathrm{x}$-ray}

This has been the mainstay of clinical management of primary and secondary pneumothorax for many years, although it is acknowledged to have limitations such as the difficulty in accurately quantifying pneumothorax size. Major technological advances in the last decade have resulted in the advent of digital chest imaging, so that conventional chest films are no longer easily available in clinical practice in the UK or in many other modern healthcare systems. The diagnostic characteristic is displacement of the pleural line. In up to $50 \%$ of cases an airfluid level is visible in the costophrenic angle, and this is occasionally the only apparent abnormality. ${ }^{33}$ The presence of bullous lung disease can lead to the erroneous diagnosis of pneumothorax, with unfortunate consequences for the patient. If uncertainty exists, then CT scanning is highly desirable (see below).

\section{Lateral x-rays}

These may provide additional information when a suspected pneumothorax is not confirmed by a PA chest film ${ }^{33}$ but, again, are no longer routinely used in everyday clinical practice.

\section{Expiratory films}

These are not thought to confer additional benefit in the routine assessment of pneumothorax. ${ }^{34-36}$

Supine and lateral decubitus $\mathrm{x}$-rays

These imaging techniques have mostly been employed for trauma patients who cannot be safely moved. They are generally less sensitive than erect PA x-rays for the diagnosis of pneumothorax $^{37} 38$ and have been superseded by ultrasound or CT imaging for patients who cannot assume the erect posture.

\section{Ultrasound scanning}

Specific features on ultrasound scanning are diagnostic of pneumothorax ${ }^{39}$ but, to date, the main value of this technique has been in the management of supine trauma patients. ${ }^{40}$

\section{Digital imaging}

Digital radiography (Picture-Archiving Communication Systems, PACS) has replaced conventional film-based chest radiography across most UK hospitals within the last 5 years, conferring considerable advantages such as magnification, measurement and contrast manipulation, ease of transmission, storage and reproduction. Relatively few studies have addressed the specific issue of pneumothorax and its diagnosis, and these have tended to focus on expert diagnosis (by consultant radiologists) and the more discriminating departmental (rather than ward-based) workstations. Even so, some difficulties were found in the diagnosis of pneumothorax in early studies. ${ }^{41} 42$ Since then there have been technological advances, such that digital imaging may now be as reliable as more conventional chest x-rays in pneumothorax diagnosis, but there have been no more recent studies to confirm this. Differences exist between the characteristics (screen size, pixel count, contrast and luminescence) and therefore the sensitivity of the more expensive departmental devices and the desktop and mobile consoles available in the ward environment. It is currently recommended that, where primary diagnostic decisions are made based on the chest x-ray, a diagnostic PACS workstation is available for image review.

In addition, digital images do not directly lend themselves to measurement and size calculations; an auxiliary function and use of a cursor is required, but this is almost certainly more accurate than using a ruler and is easy to learn to do. Nonspecialist clinicians and trainees may not always be familiar with these functions.

\section{CT scanning}

This can be regarded as the 'gold standard' in the detection of small pneumothoraces and in size estimation. ${ }^{43}$ It is also useful 
in the presence of surgical emphysema and bullous lung disease $^{44}$ and for identifying aberrant chest drain placement ${ }^{45}$ or additional lung pathology. However, practical constraints preclude its general use as the initial diagnostic modality.

\section{Size of pneumothorax}

- In defining a management strategy, the size of a pneumothorax is less important than the degree of clinical compromise. (D)

- The differentiation of a 'large' from a 'small' pneumothorax continues to be the presence of a visible rim of $>2 \mathrm{~cm}$ between the lung margin and the chest wall (at the level of the hilum) and is easily measured with the PACS system. (D)

- Accurate pneumothorax size calculations are best achieved by CT scanning. (C)

The size of pneumothoraces does not correlate well with the clinical manifestations. ${ }^{29} 30$ The clinical symptoms associated with secondary pneumothoraces are more severe in general than those associated with primary pneumothoraces, and may seem out of proportion to the size of the pneumothorax. ${ }^{27} 28$ The clinical evaluation is therefore probably more important than the size of the pneumothorax in determining the management strategy.

Commonly, the plain PA chest x-ray has been used to quantify the size of the pneumothorax. However, it tends to underestimate the size because it is a two-dimensional image while the pleural cavity is a three-dimensional structure. The 2003 BTS guidelines ${ }^{22}$ advocated a more accurate means of size calculation than its predecessor in $1993,{ }^{15}$ using the cube function of two simple measurements, and the fact that a $2 \mathrm{~cm}$ radiographic pneumothorax approximates to a $50 \%$ pneumothorax by volume. There are difficulties with this approach, including the fact that some pneumothoraces are localised (rather than uniform), so that measurement ratios cannot be applied. The shape of the lung cannot be assumed to remain constant during collapse. ${ }^{46}$ The measurement of the ratio of the lung to the hemithorax diameter is accurate and relatively easy with the new PACS systems by means of a cursor, once familiar with the PACS auxiliary functions.

The choice of a $2 \mathrm{~cm}$ depth is a compromise between the theoretical risk of needle trauma with a more shallow pneumothorax and the significant volume and length of time to spontaneous resolution of a greater depth of pneumothorax. ${ }^{47} 48$ Assuming a symmetrical pattern of lung collapse, then this measure is normally taken from the chest wall to the outer edge of the lung at the level of the hilum (figure 1). Guidelines from the $\mathrm{USA}^{49}$ estimated the volume of a pneumothorax by measuring the distance from the lung apex to the cupola, but this method would tend to overestimate the volume in a localised apical pneumothorax. Belgian guidelines have used yet another technique for measuring pneumothorax size, and comparisons between the different techniques have shown poor agreement. $^{50}$

CT scanning is regarded as the best means of establishing the size of a pneumothorax ${ }^{51}$ and has been calibrated in a lung model experiment. ${ }^{52}$

\section{TREATMENT OPTIONS FOR PNEUMOTHORAX}

- Patients with pre-existing lung disease tolerate a pneumothorax less well, and the distinction between PSP and SSP should be made at the time of diagnosis to guide appropriate management. (D)

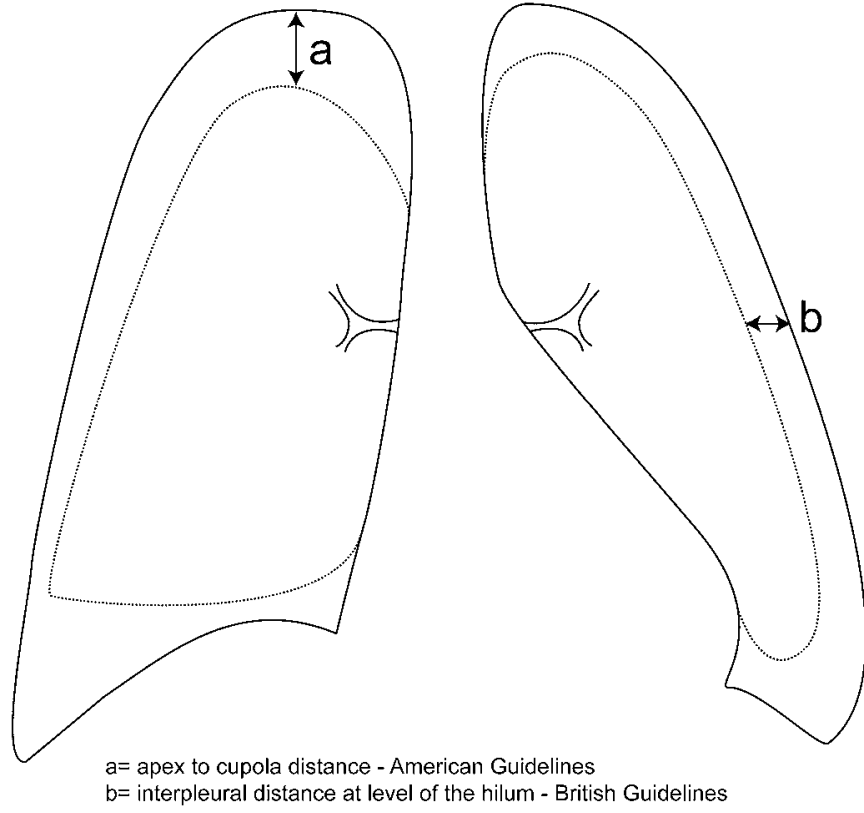

Figure 1 Depth of pneumothorax.

- Breathlessness indicates the need for active intervention as well as supportive treatment (including oxygen). (D)

- The size of the pneumothorax determines the rate of resolution and is a relative indication for active intervention. (D)

Primary pneumothorax occurs in patients with no evidence of other underlying lung disease. Although histological abnormalities are usually present, associated in particular with cigarette smoking, they have not been manifested by symptoms or loss of function. In contrast, secondary pneumothorax usually occurs in patients with overt underlying lung disease, most commonly chronic obstructive pulmonary disease (COPD). It is important to make this fundamental distinction as pneumothorax in COPD is much less well tolerated by the patient and tends to respond less favourably to management interventions and because the underlying lung disease requires appropriate treatment in addition. Several series have shown a reduced success rate for aspiration in patients aged $>50$ years as well as for chronic lung disease. It seems likely that these older patients had unrecognised underlying lung disease. This age criterion was included in the flowchart for SSP in the 2003 guidelines and is incorporated into the new flowchart (figure 2), serving as a prompt to consider the likelihood of SSP. Further criteria that are important in the decision-making process are the presence of significant breathlessness and the size of the pneumothorax. The rate of resolution/reabsorption of spontaneous pneumothoraces has been gauged as being between $1.25 \%$ and $2.2 \%$ of the volume of the hemithorax every $24 \mathrm{~h},{ }^{47} 4852$ the higher and more recent estimate ${ }^{52}$ being derived from CT volumetry. Thus, a complete pneumothorax might be expected to take up to 6 weeks to resolve spontaneously and, conceivably, in the presence of a persistent air leak, even longer.

\section{Management of PSP}

- Patients with PSP or SSP and significant breathlessness associated with any size of pneumothorax should undergo active intervention. (A)

- Chest drains are usually required for patients with tension or bilateral pneumothorax who should be admitted to hospital. (D) 


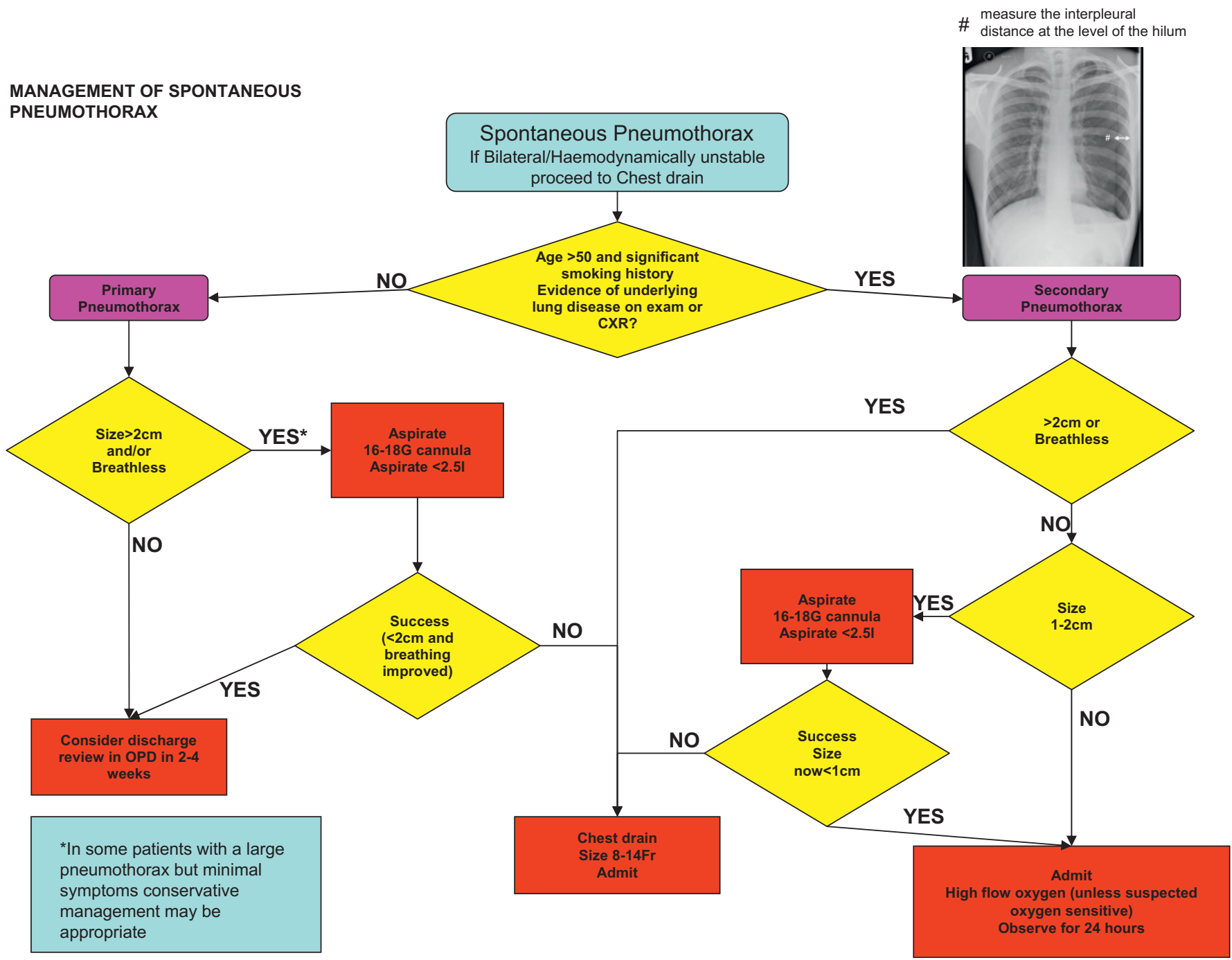

Figure 2 Flowchart of management of spontaneous pneumothorax.

- Observation is the treatment of choice for small PSP without significant breathlessness. (B)

- Selected asymptomatic patients with a large PSP may be managed by observation alone. (A)

- Patients with a small PSP without breathlessness should be considered for discharge with early outpatient review. These patients should also receive clear written advice to return in the event of worsening breathlessness. (D)

Both tension pneumothorax and bilateral pneumothorax are potentially life-threatening events that require chest drain insertion. Because such patients are generally excluded from trials of spontaneous pneumothorax, there is no evidence upon which to base recommendations, advice being based on the grounds of safe practice. Similarly, patients with associated large pleural effusions (hydropneumothorax) have also been excluded from trials, but are likely to require chest drain insertion and further investigation (see separate guideline). A summary of the management recommendations is shown in the flowchart (figure 2) with explanatory detail in the text below.

\section{Minimal symptoms}

Conservative management of small pneumothoraces has been shown to be safe, ${ }^{475354}$ and patients who are not breathless can be managed as outpatients providing they can easily seek medical attention if any deterioration in their symptoms occurs.
Up to $80 \%$ of pneumothoraces estimated as smaller than $15 \%$ have no persistent air leak, and recurrence in those managed with observation alone is less than in those treated by chest drains. ${ }^{55}$ Early review is advisable to ensure satisfactory resolution and to reinforce the advice on lifestyle. There is no evidence that active intervention improves the associated pain, which simply warrants appropriate analgesia.

\section{Symptomatic pneumothorax}

Observation alone is inappropriate for breathless patients who require active intervention (needle aspiration or chest drain insertion). Marked breathlessness in a patient with a small PSP may herald tension pneumothorax. ${ }^{55}$ If a patient is hospitalised for observation, supplemental high flow oxygen should be given where feasible. As well as correcting any arterial hypoxaemia, ${ }^{56}$ it has been shown to result in a fourfold increase in the rate of pneumothorax resolution. ${ }^{57}$ In the presence of a continued air leak, the mechanism may be a reduction in the partial pressure of nitrogen in the pleural space relative to oxygen, which is more readily absorbed. Also, a similar effect in the pleural capillaries creates a more favourable resorption gradient. ${ }^{58}$

Needle aspiration or chest drain?

- Needle (14-16 G) aspiration (NA) is as effective as large-bore $(>20 \mathrm{~F})$ chest drains and may be associated with reduced hospitalisation and length of stay. (A) 
- NA should not be repeated unless there were technical difficulties. (B)

- Following failed NA, small-bore (<14 F) chest drain insertion is recommended. (A)

- Large-bore chest drains are not needed for pneumothorax. (D)

Needle aspiration (NA) was recommended in the previous guidelines ${ }^{17} 22$ as the initial intervention for PSP on the basis of studies ${ }^{59}$ showing equivalent success to the insertion of largebore chest drains, although this was not shown in another study. ${ }^{61}$ Seldinger (catheter over guide wire) chest drains have entered widespread usage since then and further studies have been published. A randomised controlled trial in a Kuwaiti population has confirmed equivalence between NA and chest drains $(16 \mathrm{Fr}$ ), plus a reduction in hospital admission and length of stay for NA. ${ }^{62}$ A smaller study in India has also confirmed equivalence. ${ }^{63}$ Two recent case series have reported NA success rates of $69 \%{ }^{64}$ and $50.5 \%$. ${ }^{65}$ Several meta-analyses ${ }^{66-68}$ were limited by the small numbers of patients and studies ${ }^{69-77}$ but confirm equivalence, with NA success rates ranging from $30 \%$ to $80 \%$ (see evidence table available on the BTS website www.britthoracic.org.uk). If undertaken, NA should cease after 2.51 of air has been aspirated, further re-expansion being unlikely ${ }^{59}$ because of the likely presence of a persistent air leak.

Guidelines that encourage NA are not always followed ${ }^{78-82}$ and the ease of insertion of small-bore ( $<14 \mathrm{~F}$ ) Seldinger chest drains may be regarded as a simpler option to NA. Their success has been documented in several studies, ${ }^{83-89}$ the attachment of Heimlich valves facilitating mobilisation and outpatient care. Small-bore chest drains have been shown to have a similar success rate to larger drains ${ }^{90}$ while being less painful, ${ }^{91}{ }^{92}$ but there have been no randomised controlled trials comparing them with NA. More detail on chest drain insertion and management and complications of chest drain insertion are found in the guideline on pleural procedures. Catheter aspiration was described in the last guideline, ${ }^{22}$ with success in up to $59 \%$, and further improvement with the addition of Heimlich valves and suction. ${ }^{93-95}$ Seldinger chest drains have also permitted a 'stepwise' approach to PSP management, following a predefined pathway that culminates in surgical referral where there is a persistent air leak. ${ }^{96}$

The choice of initial intervention for PSP should take into account operator experience and patient choice; NA is less painful than chest drain insertion ${ }^{60}$ but failure in approximately one-third of patients will require a second procedure. Other national and consensus guidelines recommend either NA or small-bore chest drain insertion, ${ }^{97}$ or chest drain insertion alone. ${ }^{49}$ We believe that NA remains the procedure of first choice in most cases. Repeat NA is unlikely to be successful unless there were technical difficulties such as a blocked or kinked catheter. There is some limited evidence that VATS is the preferred 'salvage' strategy after failed $N A,{ }^{98}$ but this is not the usual practice currently in the UK where small-bore chest drain insertion is usually employed. Following successful NA, the patient can be considered for hospital discharge.

\section{Suction}

- Suction should not be routinely employed. (B)

- Caution is required because of the risk of RPO. (B)

- High-volume low-pressure suction systems are recommended. (C)

A persistent air leak with or without incomplete re-expansion of the lung is the usual reason for consideration of the use of suction, although there is no evidence for its routine use. ${ }^{99-101}$ It is arbitrarily defined as the continued bubbling of air through a chest drain after $48 \mathrm{~h}$ in situ. A retrospective review of 142 cases of pneumothorax ${ }^{102}$ found a median time to resolution of 8 days which was not related to the initial size of pneumothorax, but longer for SSP. A persistent air leak was observed in 43 cases, 30 of which were treated with suction. The theory that underpins the role of suction is that air might be removed from the pleural cavity at a rate that exceeds the egress of air through the breach in the visceral pleura and to subsequently promote healing by apposition of the visceral and parietal pleural layers. It has been suggested that optimal suction should entail pressures of -10 to $-20 \mathrm{~cm} \mathrm{H}_{2} \mathrm{O}$ (compared with normal intrapleural pressures of between -3.4 and $-8 \mathrm{~cm} \mathrm{H}_{2} \mathrm{O}$, according to the respiratory cycle), with the capacity to increase the air flow volume to $15-20 \mathrm{l} / \mathrm{min}^{103}$ Other forms of suction are not recommended. High-pressure high-volume suction may lead to air stealing, hypoxaemia or the perpetuation of air leaks. ${ }^{104}$ Likewise, high-pressure low-volume systems should be avoided. ${ }^{105}$ High-volume low-pressure systems such as VernonThompson pumps or wall suction with low pressure adaptors are therefore recommended.

The addition of suction too early after chest drain insertion may precipitate RPO, especially in the case of a PSP that may have been present for more than a few days, ${ }^{106}$ and is thought to be due to the additional mechanical stress applied to capillaries that are already 'leaky'. ${ }^{107}$ The clinical manifestations are cough, breathlessness and chest tightness after chest drain insertion. The incidence may be up to $14 \%$ (higher in younger patients with a large PSP), although no more than a radiological phenomenon in the majority of cases. ${ }^{106}$ Sometimes pulmonary oedema is evident in the contralateral lung. ${ }^{108}$ Fatalities have been reported in as many as $20 \%$ of 53 cases in one series, ${ }^{108}$ so caution should be exercised in this particular group of patients.

Specialist referral

- Referral to a respiratory physician should be made within $24 \mathrm{~h}$ of admission. (C)

- Complex drain management is best effected in areas where specialist medical and nursing expertise is available. (D)

Failure of a pneumothorax to re-expand or a persistent air leak should prompt early referral to a respiratory physician, preferably within the first $24 \mathrm{~h}$. Such patients may require prolonged chest drainage with complex drain management (suction, chest drain repositioning) and liaison with thoracic surgeons. Drain management is also best delivered by nurses with specialist expertise. Surgical referral is discussed in a later section.

\section{Surgical emphysema}

This is a well-recognised complication of chest drainage. ${ }^{109}$ Generally it is of cosmetic importance only, although alarming for patients and their relatives, and subsides spontaneously after a few days. It is usually seen in the context of a malpositioned, kinked, blocked or clamped chest drain. It can also occur with an imbalance between a large air leak and a relatively small-bore chest drain. Occasionally, acute airway obstruction or thoracic compression may lead to respiratory compromise 109110 in which case tracheostomy, skin incision decompression and insertion of large-bore chest drains have all been used. ${ }^{109}$ For most, the treatment is conservative.

\section{Management of SSP}

- All patients with SSP should be admitted to hospital for at least $24 \mathrm{~h}$ and receive supplemental oxygen in 
compliance with the BTS guidelines on the use of oxygen. (D)

- Most patients will require the insertion of a small-bore chest drain. (B)

- All patients will require early referral to a chest physician. (D)

- Those with a persistent air leak should be discussed with a thoracic surgeon at $\mathbf{4 8} \mathrm{h}$. (B)

As stated previously, SSP is less likely to be tolerated by patients than PSP because of co-existing lung disease. Furthermore, the air leak is less likely to settle spontaneously, ${ }^{111} 112$ so that most patients will require active intervention. Oxygen is indicated, ${ }^{56} 57$ but caution is required for patients with carbon dioxide retention. ${ }^{113}$ Aspiration is less likely to be successful in SSP (see evidence table available on the BTS website at www.brit-thoracic.org.uk) but can be considered in symptomatic patients with small pneumothoraces in an attempt to avoid chest drain insertion. Otherwise, the insertion of a small-bore chest drain is recommended, a study in $\mathrm{SSP}^{114}$ having found equivalent success to the use of large drains. Early referral to a chest physician is encouraged for all patients with SSP, both for management of the pneumothorax and also of the underlying lung disease. Similarly, those with a persistent air leak should be discussed with a thoracic surgeon after $48 \mathrm{~h},{ }^{112} 115$ even though many will resolve spontaneously if managed conservatively for as long as 14 days. ${ }^{111}$

Patients with SSP but unfit for surgery

- Medical pleurodesis may be appropriate for inoperable patients. (D)

- Patients with SSP can be considered for ambulatory management with a Heimlich valve. (D)

These patients are at heightened risk of a persistent air leak but may not be fit for surgical intervention by virtue of the severity of their underlying lung disease, or they may be unwilling to proceed. Their optimal management is challenging and requires close medical and surgical liaison. Medical pleurodesis is an option for such patients, as is ambulatory management with the use of a Heimlich valve. ${ }^{86}$

\section{DISCHARGE AND FOLLOW-UP}

- Patients should be advised to return to hospital if increasing breathlessness develops. (D)

- All patients should be followed up by respiratory physicians until full resolution. (D)

- Air travel should be avoided until full resolution. (C)

- Diving should be permanently avoided unless the patient has undergone bilateral surgical pleurectomy and has normal lung function and chest CT scan postoperatively. (C)

All patients discharged after active treatment or otherwise should be given verbal and written advice to return to the Accident and Emergency department immediately should they develop further breathlessness. It is recommended that all patients should be followed up by a respiratory physician to ensure resolution of the pneumothorax, to institute optimal care of any underlying lung disease, to explain the risk of recurrence and the possible later need for surgical intervention and to reinforce lifestyle advice on issues such as smoking and air travel. Those managed by observation alone or by NA should be advised to return for a follow-up chest x-ray after 2-4 weeks to monitor resolution. Those with successful lung re-expansion before hospital discharge will also require early review because recurrence may occur relatively early.
Since there is no evidence to link recurrence with physical exertion, the patient can be advised to return to work and to resume normal physical activities once all symptoms have resolved, although it is reasonable to advise that sports that involve extreme exertion and physical contact should be deferred until full resolution. Patients should be made aware of the danger of air travel in the presence of a current closed pneumothorax, and should be cautioned against commercial flights at high altitude until full resolution of the pneumothorax has been confirmed by a chest x-ray. While there is no evidence that air travel per se precipitates pneumothorax recurrence, the consequences of a recurrence during air travel may be serious. Many commercial airlines previously advised arbitrarily a 6-week interval between the pneumothorax event and air travel, but this has since been amended to a period of 1 week after full resolution. The BTS guidelines on air travel ${ }^{116}$ emphasise that the recurrence risk only significantly falls after a period of 1 year from the index pneumothorax so that, in the absence of a definitive surgical procedure, patients with SSP in particular may decide to minimise the risk by deferring air travel accordingly. After a pneumothorax, diving should be discouraged permanently ${ }^{117}$ unless a very secure definitive prevention strategy has been performed such as surgical pleurectomy. The BTS guidelines on respiratory aspects of fitness for diving ${ }^{118}$ deal with this in greater detail. Smoking influences the risk of recurrence, ${ }^{12} 15$ so cessation should be advised. Pregnancy is an issue to be discussed with younger female patients.

\section{MEDICAL CHEMICAL PLEURODESIS}

- Chemical pleurodesis can control difficult or recurrent pneumothoraces (A) but, since surgical options are more effective, it should only be used if a patient is either unwilling or unable to undergo surgery. (B)

- Chemical pleurodesis for pneumothorax should only be performed by a respiratory specialist. (C)

Chemical pleurodesis has generally been advocated by respiratory physicians experienced in thoracoscopy. The instillation of substances into the pleural space should lead to an aseptic inflammation, with dense adhesions leading ultimately to pleural symphysis. There is a significant rate of recurrence of both primary and secondary pneumothoraces, ${ }^{12}$ and efforts to reduce recurrence by instilling various sclerosants-either via a chest drain, video-assisted thoracoscopic surgery (VATS) or open surgery-are often undertaken without clear guidelines to direct physicians in their use. In the vast majority of cases the prevention of recurrent pneumothoraces should be undertaken surgically using either an open or VATS approach, as the rate of recurrence following surgical pleurodesis via thoracotomy or VATS is far less than following simple medical pleurodesis with chemical agents, ${ }^{32}$ 119-121 although direct comparative trials are lacking. A small number of patients are either too frail or are unwilling to undergo any surgical treatment and, in these situations, medical chemical pleurodesis may be appropriate.

Many sclerosing agents suitable for instillation into the pleural space have been studied. ${ }^{32} 119122-125$ Tetracycline used to be recommended as the first-line sclerosant therapy for both primary and secondary pneumothoraces as it proved to be the most effective sclerosant in animal models. ${ }^{123} 126127$ Recently, however, parenteral tetracycline for pleurodesis has become more difficult to obtain owing to problems with the manufacturing process. Minocycline and doxycycline have also been shown to be reasonable alternative sclerosing agents in animal models. ${ }^{126} 127$ 
The rate of recurrence of pneumothorax is the primary indicator for success for any recurrence prevention techniques. Although tetracycline has been shown to reduce the incidence of early recurrence, the incidence of late recurrence remains at $10-20 \%$ which is unacceptably high when compared with surgical methods of pleurodesis. ${ }^{119} 121125128129$ Tetracycline can be recommended for recurrent primary and secondary pneumothorax when surgery is not an option, and graded talc may also be used on the grounds that it is the most effective agent in treating malignant pleural effusion and is also commonly used for surgical chemical pleurodesis. ${ }^{130-133}$ There is conflicting evidence as to whether tetracycline is effective for the treatment of a fully expanded pneumothorax with a persistent air leak. ${ }^{32} 134135$ The largest of these studies, the Veterans Administration Study, did not support the use of intrapleural tetracycline to facilitate the closure of a persistent air leak. ${ }^{31}$ Macoviak and colleagues ${ }^{135}$ suggest that intrapleural tetracycline can facilitate the closure of a persistent air leak provided the lung can be kept expanded so that symphysis can occur. Likewise, there is conflicting evidence as to whether intrapleural tetracycline shortens the length of stay in hospital with pneumothorax. ${ }^{32} 119125$

The dosage of intrapleural tetracycline requires clarification. Almind ${ }^{119}$ found a reduction in the recurrence rate in a group receiving $500 \mathrm{mg}$ tetracycline via chest drains compared with those treated by tube drainage alone. This reduction was not significant. The Veterans Administration Study, ${ }^{32}$ which used $1500 \mathrm{mg}$ tetracycline, showed a significant reduction in the recurrence rate of pneumothorax without significant extra morbidity. This dose of intrapleural tetracycline is therefore recommended as the standard dose for medical pleurodesis. While pain was reported more frequently in the group treated with tetracycline at a dose of $1500 \mathrm{mg},{ }^{32}$ others have reported no increase in pain with doses of $500 \mathrm{mg}$ provided adequate analgesia is given. ${ }^{119}$ Adequate analgesia may be achieved with the administration of intrapleural local anaesthesia. Standard doses (200 mg (20 ml) of 1\% lidocaine) are significantly less effective than larger doses $(250 \mathrm{mg}(25 \mathrm{ml})$ of $1 \%$ lidocaine), the higher doses having been shown to increase the number of pain-free episodes from $10 \%$ to $70 \%$ with no appreciable toxicity. ${ }^{136}$

Chemical pleurodesis using graded talc is an effective alternative to tetracycline pleurodesis, but there are no controlled trials comparing the two in the treatment of pneumothorax. The issue of talc pleurodesis is discussed in the later section on surgical chemical pleurodesis as most trials using talc relate to its use in either thoracoscopic or open surgical techniques. Since we recognise chemical pleurodesis as an inferior option to surgical pleurodesis, we recommend that chemical pleurodesis should be undertaken by respiratory physicians or thoracic surgeons only.

\section{REFERRAL TO THORACIC SURGEONS}

- In cases of persistent air leak or failure of the lung to reexpand, an early (3-5 days) thoracic surgical opinion should be sought. (C)

There is no evidence on which to base the ideal timing for thoracic surgical intervention in cases of persistent air leak. A cutoff point of 5 days has been widely advocated in the past ${ }^{55}$ but is arbitrary. Chee et al ${ }^{111}$ showed that $100 \%$ of primary pneumothoraces with a persistent air leak for $>7$ days and treated by tube drainage had resolved by 14 days. Also, $79 \%$ of those with secondary pneumothoraces and a persistent air leak had resolved by 14 days, with no mortality in either group. However, surgical intervention carries a low morbidity ${ }^{128} 1291^{137-140}$ and postsurgical recurrence rates are low. ${ }^{128} 129$ Surgical intervention as early as 3 days has advocates, ${ }^{141} 142$ but there is no evidence that intervention before 5 days is necessary for PSP. Each case should be assessed individually on its own merit. Patients with pneumothoraces should be managed by a respiratory physician, and a thoracic surgical opinion will often form an early part of the management plan.

Accepted indications for surgical advice should be as follows:

- Second ipsilateral pneumothorax.

- First contralateral pneumothorax.

- Synchronous bilateral spontaneous pneumothorax.

- Persistent air leak (despite 5-7 days of chest tube drainage) or failure of lung re-expansion.

- Spontaneous haemothorax. ${ }^{143} 144$

- Professions at risk (eg, pilots, divers). ${ }^{111} 138$ 145-147

- Pregnancy.

Increasingly, patient choice will play a part in decisionmaking, and even those without an increased risk in the event of a pneumothorax because of their profession may elect to undergo surgical repair after their first pneumothorax, ${ }^{148} 149$ weighing the benefits of a reduced recurrence risk against that of chronic pain, ${ }^{150}$ paraesthesia ${ }^{151}$ or the possibility of increased costs. ${ }^{152}$

\section{Surgical strategies: open thoracotomy or VATS?}

- Open thoracotomy and pleurectomy remain the procedure with the lowest recurrence rate (approximately $1 \%$ ) for difficult or recurrent pneumothoraces. (A)

- Video-assisted thoracoscopic surgery (VATS) with pleurectomy and pleural abrasion is better tolerated but has a higher recurrence rate of approximately $5 \%$. (A)

There are two main objectives in the surgical repair of persistent air leak from a pneumothorax and in the prevention of recurrence. The first objective is to resect any visible bullae or blebs on the visceral pleura and also to obliterate emphysema-like changes $^{9}$ or pleural porosities under the surface of the visceral pleura. ${ }^{8}$ The second objective is to create a symphysis between the two opposing pleural surfaces as an additional means of preventing recurrence. In the past, surgeons have tended to favour a surgical pleurodesis with pleural abrasion while others have stressed the importance of various degrees of pleurectomy in recurrence prevention. ${ }^{137153154}$ Although there may be slight advantages of pleurectomy over pleural abrasion, ${ }^{137}$ a combination of the two is often used. ${ }^{155-158}$ Unfortunately there is a paucity of good comparative case-controlled studies in this area. ${ }^{128} 129$ In recent years, less invasive procedures using VATS have become more popular with lower morbidity although with slightly higher recurrence rates.

Open thoracotomy with pleural abrasion was the original surgical treatment for pneumothorax, described by Tyson and Crandall in 1941. ${ }^{159}$ In 1956 Gaensler introduced parietal pleurectomy for recurrent pneumothoraces, encouraging pleural symphysis through adhesions between the visceral pleura and the chest wall. ${ }^{153}$ Closure of the leaking visceral pleura with direct cautery and ligation or suture of associated blebs ${ }^{147}$ is also thought to be important. Although open thoracotomy has the lowest pneumothorax recurrence rates, there are also lesser surgical procedures with comparable recurrence rates but less morbidity. ${ }^{160}$ These include transaxillary minithoracotomy, using a $5-6 \mathrm{~cm}$ incision in the axillary margin with apical pleurectomy and pleural abrasion, introduced in the 1970s. ${ }^{161}$ Open thoracotomy is generally performed with a limited posterolateral approach and single lung ventilation. This allows for a parietal pleurectomy with excision, stapling or ligation of visible bullae and pleural abrasion. ${ }^{162}$ Isolated lung ventilation during open thoracotomy 
renders easier visualisation of the visceral pleura than during a VATS procedure. ${ }^{163-165}$ Meta-analyses of studies comparing open with limited or VATS procedures ${ }^{128} 129$ have shown lower recurrence rates (approximately 1\%) with open procedures but greater blood loss, more postoperative pain ${ }^{166}$ and longer hospital stays. ${ }^{167}$ Some non-randomised studies have found no significant differences. ${ }^{168} 169$ A complicated meta-analysis of three retrospective studies and one prospective study comparing the cost of open thoracotomy versus VATS (not exclusively for pneumothoraces) concluded that the total economic cost of VATS was lower, ${ }^{170}$ and it can be undertaken without general anaesthesia. ${ }^{149}$ There is a need for better quality prospective randomised studies in this area. Several authors suggest that VATS offers a significant advantage over open thoracotomy, including a shorter postoperative hospital stay, ${ }^{145} 162167171-173$ less postoperative pain ${ }^{160} 162166174175$ and improved pulmonary gas exchange postoperatively, ${ }^{176}$ although not all trials have confirmed shorter hospital stays with VATS. ${ }^{169} 177$

Much of the literature contains heterogeneous comparisons between PSP and SSP, but the most recent 'clinical bottom line ${ }^{, 129}$ concludes that VATS pleurectomy is comparable to open pleurectomy, with several randomised controlled trials showing reductions in length of hospital stay, analgesic requirement and postoperative pulmonary dysfunction. Clearly this needs to be weighed against the slight increase in recurrence rate when using a less invasive approach. ${ }^{128}$

\section{Surgical chemical pleurodesis}

- Surgical chemical pleurodesis is best achieved by using $5 \mathrm{~g}$ sterile graded talc, with which the complications of adult respiratory distress syndrome and empyema are rare. (A)

With the advent of VATS for pneumothorax repair and recurrence prevention, the use of surgical chemical pleurodesis has declined significantly. Previous reports have shown that talc can achieve pleurodesis successfully in $85-90 \%$ of cases, similar to other thoracoscopic techniques for complicated pneumothorax. ${ }^{121} 145171178179$ A meta-analysis of the success rates of talc pleurodesis in the treatment of pneumothorax shows an overall success rate of $91 \% .{ }^{178}$ Graded talc is preferable to tetracycline, which is less available now, and is associated with much higher recurrence rates. ${ }^{120}$ Much of the literature concerning the use of talc in achieving pleurodesis relates to its use in the control of malignant pleural effusions, although talc poudrage has been used successfully in secondary pneumothoraces. ${ }^{180}$ On the basis of a systematic review of uncontrolled trials, $5 \mathrm{~g}$ of intrapleural talc via VATS achieves a success rate of $87 \%$. ${ }^{178}$

The adult respiratory distress syndrome has been described following the use of talc. This probably relates to the size of the talc particles ${ }^{181}$ and is unlikely to occur with the use of graded talc. ${ }^{182} 183$ If talc is correctly sterilised, the incidence of empyema is very low. ${ }^{178} 184185$ There does not appear to be a difference between talc poudrage and talc slurry pleurodesis. The advent of successful and well-tolerated VATS surgery will lead to less use of surgical chemical pleurodesis with talc. In those patients who are either unwilling or too unwell to undergo a VATS procedure, then medical pleurodesis with talc via a chest drain would be the preferred option.

\section{TENSION PNEUMOTHORAX}

- Tension pneumothorax is a medical emergency that requires heightened awareness in a specific range of clinical situations. (D)
- Treatment is with oxygen and emergency needle decompression. (D)

- A standard cannula may be insufficiently long if used in the second intercostal space. (D)

This is a medical emergency that can arise in a variety of clinical situations, so a high index of suspicion is required in order to make the correct diagnosis and to manage it effectively. The most frequent situations are shown in box 1, although the list does not include all eventualities. It arises as a result of the development of a one-way valve system at the site of the breach in the pleural membrane, permitting air to enter the pleural cavity during inspiration but preventing egress of air during expiration, with consequent increase in the intrapleural pressure such that it exceeds atmospheric pressure for much of the respiratory cycle. As a result, impaired venous return and reduced cardiac output results in the typical features of hypoxaemia and haemodynamic compromise. ${ }^{186} 187$

A recent review ${ }^{188}$ has emphasised the important differences between the presentation in ventilated and non-ventilated patients, where it is typically seen after trauma or resuscitation. The former group is associated with a uniformly rapid presentation with hypotension, tachycardia, falling oxygen saturation and cardiac output, increased inflation pressures and cardiac arrest. This is frequently missed in the ICU setting ${ }^{37}$ and can also occur after nasal non-invasive ventilation (NIV). The latter group of awake patients show a greater variability of presentations which are generally progressive with slower decompensation. Tachypnoea, tachycardia and hypoxaemia lead eventually to respiratory arrest. Apart from these general physical signs, the most frequent lateralising sign found in a review of 18 case reports ${ }^{188}$ was that of decreased air entry $(50-75 \%)$, with signs of tracheal deviation, hyperexpansion, hypomobility and hyperresonance present only in the minority.

In neither group is imaging especially helpful; there is usually insufficient time to obtain a chest x-ray and, even if available, the size of the pneumothorax or the presence of mediastinal displacement correlate poorly with the presence of tension within a pneumothorax. However, a chest x-ray can, when time is available, confirm the presence of a pneumothorax (if uncertain) and the correct side.

Treatment is with high concentration oxygen and emergency needle decompression, a cannula usually being introduced in the second anterior intercostal space in the mid-clavicular line. The instantaneous egress of air through the majority of the respiratory cycle is an important confirmation of the diagnosis and the correct lateralisation. A standard 14 gauge $(4.5 \mathrm{~cm})$ cannula may not be long enough to penetrate the parietal pleura, however, with up to one-third of patients having a chest wall thickness

Box 1 Typical clinical situations where tension pneumothorax arises

1. Ventilated patients on ICU.

2. Trauma patients.

3. Resuscitation patients (CPR).

4. Lung disease, especially acute presentations of asthma and chronic obstructive pulmonary disease.

5. Blocked, clamped or displaced chest drains.

6. Patients receiving non-invasive ventilation (NIV).

7. Miscellaneous group, for example patients undergoing hyperbaric oxygen treatment. 
$>5 \mathrm{~cm}$ in the second interspace. ${ }^{189}$ The chest wall may be less deep in the fourth or fifth interspace, and this could provide an alternative site for decompression or a chest drain may need to be inserted if there is an initial treatment failure. In any case, a chest drain should be inserted immediately after needle decompression and the cannula left in place until bubbling is confirmed in the underwater seal system to confirm proper function of the chest drain. ${ }^{186}$

\section{PNEUMOTHORAX AND PREGNANCY}

- Pneumothorax recurrence is more common in pregnancy, poses risks to the mother and fetus, and requires close cooperation between chest physicians, obstetricians and thoracic surgeons. (C)

- The modern and less invasive strategies of simple observation and aspiration are usually effective during pregnancy, with elective assisted delivery and regional anaesthesia at or near term. (C)

- A corrective surgical procedure (VATS) should be considered after delivery. (D)

Although less common in women than in men, the occurrence of PSP in women of childbearing age is not unusual. There appears to be an increased risk of recurrence during pregnancy and during parturition, ${ }^{190}$ with potential risks to the mother and fetus. The earlier literature consists largely of case reports and described varied and relatively invasive management strategies such as prolonged intrapartum chest tube drainage, intrapartum thoracotomy, premature induction of labour or caesarean section. A more recent case series and literature review ${ }^{191}$ has recommended the use of more modern conservative management methods for which favourable outcomes have now been experienced. Pneumothorax that occurs during pregnancy can be managed by simple observation if the mother is not dyspnoeic, there is no fetal distress and the pneumothorax is small $(<2 \mathrm{~cm})$. Otherwise aspiration can be performed, chest drain insertion being reserved for those with a persistent air leak.

Close cooperation between the respiratory physician, obstetrician and thoracic surgeon is essential. To avoid spontaneous delivery or caesarean section, both of which have been associated with an increased risk of recurrence, the safest approach will usually be that of elective assisted delivery (forceps or ventouse extraction) at or near term, with regional (epidural) anaesthesia. Less maternal effort is required with forceps delivery, which is therefore preferable. If caesarean section is unavoidable because of obstetric considerations, then a spinal anaesthetic is preferable to a general anaesthetic.

Because of the risk of recurrence in subsequent pregnancies, a minimally invasive VATS surgical procedure should be considered after convalescence. Successful pregnancies and spontaneous deliveries without pneumothorax recurrence have been reported after a VATS procedure. ${ }^{191}$

\section{CATAMENIAL PNEUMOTHORAX}

- Catamenial pneumothorax is underdiagnosed in women with pneumothorax. (C)

- A combination of surgical intervention and hormonal manipulation requires cooperation with thoracic surgeons and gynaecologists. (D)

Catamenial is a term that derives from the Greek meaning 'monthly'. The typical combination of chest pain, dyspnoea and haemoptysis occurring within $72 \mathrm{~h}$ before or after menstruation in young women has been thought to be relatively rare. There are approximately 250 cases described in the medical literature, ${ }^{192}$ but it is likely that the majority of cases are not reported. Most of these references are of solitary case reports or small series. The associated pneumothorax is usually right-sided and there is a heightened tendency to recurrence coinciding with the menstrual cycle. Many cases have evidence of pelvic endometriosis. Although the aetiology is not fully understood, inspection of the pleural diaphragmatic surface at thoracoscopy often reveals defects (termed fenestrations) as well as small endometrial deposits. These deposits have also been seen on the visceral pleural surface. Among women undergoing routine surgical treatment for recurrent pneumothorax, however, catamenial pneumothorax has been diagnosed in as many as $25 \% .{ }^{193}$ Thus, it may be relatively underdiagnosed.

Extragenital or 'ectopic' endometriosis is an uncommon condition that can affect almost any organ system and tissue within the body, the thorax being the most frequent extrapelvic location. What has been termed the thoracic endometriosis syndrome (TES) includes catamenial pneumothorax, catamenial haemothorax, catamenial haemoptysis and lung nodules (purple or brown coloured). The most accepted theory to explain the phenomenon of catamenial pneumothorax is that of aspiration of air from the abdomen and genital tract via the diaphragmatic fenestrations, but the appearance of endometriosis deposits on the visceral pleural surface raises the possibility that erosion of the visceral pleura might be an alternative mechanism. Haemoptysis is thought to result from intrapulmonary endometriosis deposits, the mechanism by which endometrial tissue reaches the lung being poorly understood.

The management strategies can be divided into thoracic surgical techniques and hormonal manipulation although, in the past, total abdominal hysterectomy and bilateral salpingohysterectomy have been employed. Thoracic surgical techniques have been varied and include diaphragmatic resection or plication of the fenestrations seen at thoracoscopy, the insertion of a mesh or patch over these fenestrations, electrocoagulation of the endometriosis deposits and pleurodesis. This variability reflects the general lack of success with surgical intervention alone, recurrence rates of up to $30 \%$ being documented. ${ }^{194}$ When combined with gonadotrophin-releasing hormone analogues amenorrhoea results, but recurrence has been avoided with follow-up approaching periods of 4 years. ${ }^{195}$ Successful patient management requires close cooperation between respiratory physicians, thoracic surgeons and gynaecologists.

\section{PNEUMOTHORAX AND AIDS}

- The combination of pneumothorax and HIV infection requires early intercostal tube drainage and surgical referral, in addition to appropriate treatment for HIV and PJP infection. (C)

Over the course of the last 20 years a strong association has been observed between HIV infection and pneumothorax. Historically, up to $5 \%$ of AIDS patients developed pneumothorax ${ }^{196-198}$ and up to $25 \%$ of spontaneous pneumothoraces occurred in HIV-infected patients in large urban settings where a high prevalence occurred. ${ }^{27} 28199$ Pneumocystis jiroveci (PJP)previously known as Pneumocystis carinii (PCP) - infection has been considered to be the main aetiological factor for this association, because of a severe form of necrotising alveolitis that occurs in which the subpleural pulmonary parenchyma is replaced by necrotic thin-walled cysts and pneumatoceles. ${ }^{200} 201$ The administration of nebulised pentamidine has also been suggested as a possible independent risk factor. ${ }^{196}$ The use of systemic corticosteroids may also contribute to the morbidity in such patients. ${ }^{202}$ 
Due to the histopathology outlined above, pneumothoraces caused by PJP have a tendency to more prolonged air leaks, treatment failure, recurrence and higher hospital mortality. ${ }^{203}$ Up to $40 \%$ of these patients can develop bilateral pneumothorax. Treatment failures have been observed to correlate with the degree of immunosuppression, as reflected by CD4 counts. ${ }^{203}$ In view of these features, management strategies have been evolved that incorporate early and aggressive intervention including tube drainage, pleurodesis and surgical techniques such as pleurectomy. ${ }^{197} 199202-205$ Observation and simple aspiration are not likely to suffice, even in the first instance.

Over the last 5 years, and since the last BTS guidelines, the global spectrum of HIV infection has changed significantly as a result of the more widespread use of both antiretroviral therapy and PJP prophylaxis. While the disease burden remains very high in the underdeveloped world, the prognosis for such patients in Western societies has greatly improved, ${ }^{206}$ where this combination is now much less frequently encountered. As HIV is now becoming a more chronic disease associated with a high incidence of smoking and therefore of COPD, pneumothoraces might become more significant when they occur.

However, the mortality of patients who require intensive care for PJP in HIV infection remains high, especially when pneumothorax occurs during ventilation. Although antiretroviral therapy that is commenced before or during hospitalisation can improve the outcome, ${ }^{207}$ the potential risk of the 'immune reconstitution syndrome' has to be taken into consideration.

\section{PNEUMOTHORAX AND CYSTIC FIBROSIS}

- The development of a pneumothorax in a patient with cystic fibrosis requires early and aggressive treatment with early surgical referral. (C)

- Pleural procedures, including pleurodesis, do not have a significant adverse effect on the outcome of subsequent lung transplantation. (D)

Even though long-term survival has improved significantly, spontaneous pneumothorax remains a common complication of cystic fibrosis, occurring in $0.64 \%$ of patients per annum and $3.4 \%$ of patients overall. ${ }^{208}$ It occurs more commonly in older patients and those with more advanced lung disease, and is associated with a poor prognosis, the median survival being 30 months. ${ }^{209}$ Contralateral pneumothoraces occur in up to $40 \%$ of patients. ${ }^{209} 210 \mathrm{An}$ increased morbidity also results, with increased hospitalisation and a measurable decline in lung function. ${ }^{208}$ While a small pneumothorax without symptoms can be observed or aspirated, larger pneumothoraces require a chest drain. The collapsed lung can be stiff and associated with sputum retention, thus requiring a longer time to re-expand. During this time other general measures, such as appropriate antibiotic treatment, are needed.

Chest tube drainage alone has a recurrence rate of $50 \%$, but interventions such as pleurectomy, pleural abrasion and pleurodesis have lower rates. ${ }^{211-213}$ With a success rate of $95 \%$ and with little associated reduction in pulmonary function, partial pleurectomy is generally regarded as the treatment of choice in patients with cystic fibrosis and recurrent pneumothoraces who are fit to undergo surgery. ${ }^{209}$ In those who are not fit for surgery and in whom re-expansion may take several weeks with a chest drain and suction, pleurodesis offers an alternative strategy. ${ }^{209}$ This had been thought to be a relative contraindication to later transplantation because of the need for a lengthier transplant procedure and excessive bleeding. ${ }^{214} \mathrm{~A}$ more recent study ${ }^{215}$ has concluded that previous pleural procedures should not be considered as a contraindication for transplantation, there being no significant effect on surgical outcome although more dense pleural adhesions were observed than in a control population.

\section{IATROGENIC PNEUMOTHORAX}

Iatrogenic pneumothorax has been shown to be even more common than spontaneous pneumothorax in several large reviews, ${ }^{216} 217$ the most common causes being transthoracic needle aspiration (24\%), subclavian vessel puncture $(22 \%)$, thoracocentesis (22\%), pleural biopsy (8\%) and mechanical ventilation $(7 \%) .{ }^{218} \mathrm{It}$ is also a complication of transbronchial biopsy. During transthoracic needle aspiration the two primary risk factors are the depth of the lesion and the presence of COPD. ${ }^{219}$ A large retrospective survey in the USA found an incidence of $2.68 \%$ among patients undergoing thoracocentesis. ${ }^{20}$ No means of reducing this risk has yet been identified. Positioning of the patient so that the procedure is performed in a dependent area has had no beneficial effect. ${ }^{221}$ Excluding iatrogenic penumothorax that occurs in intensive care units, the treatment seems to be relatively simple with less likelihood of recurrence (the underlying risk factors for SP not usually being present). The majority resolve spontaneously by observation alone. If intervention is required, simple aspiration has been shown to be effective in $89 \%$ of patients. ${ }^{94}$ For the remainder a chest drain is required, this being more likely in patients with COPD. ${ }^{222}$

In the intensive care unit iatrogenic pneumothorax is a lifethreatening complication that may be seen in up to $3 \%$ of patients. ${ }^{223}$ Those on positive pressure ventilation require chest drain insertion as positive pressure maintains the air leak. ${ }^{224}$

\section{CONCLUDING REMARKS}

These pneumothorax guidelines differ from the last (2003) BTS guidelines in that they have been produced in accordance with the SIGN methodology and therefore have necessitated a careful analysis of the current underlying evidence. Unfortunately there are relatively few adequate studies that address the main areas of uncertainty, and few additions to the knowledge base in the last 7 years. Nevertheless, some subtle changes in practice have occurred. These are incorporated, together with coverage of some additional topics of relevance such as catamenial pneumothorax and the issue of pneumothorax in pregnancy. The treatment algorithm is now illustrated on a single flowchart for both PSP and SSP and places slightly less emphasis on the size of the pneumothorax and more on the clinical features. However, the trend towards more conservative management is maintained, with observation for many patients with PSP, aspiration for the remainder, and smallbore chest drains for persistent air leaks. The imaging of pneumothorax has undergone a major change due to the advent of PACS technology, and the implications of this are now described. Surgical practice has also developed with the widespread adoption of less invasive (VATS) procedures rather than open thoracotomies. While the challenge of pneumothorax management in patients with cystic fibrosis remains, there has been a significant reduction in pneumothorax in patients with HIV since the introduction of antiretroviral therapy and PJP prophylactic therapy, in the countries with advanced healthcare systems at least. It is hoped that these guidelines build upon their predecessors and lead to improved care for patients with pneumothorax, and that they inform and support the clinicians who care for them.

Competing interests No member of the Guideline Group is aware of any competing interests.

Provenance and peer review The draft guideline was available for online public consultation (July/August 2009) and presented to the BTS Winter Meeting (December 2009). Feedback was invited from a range of stakeholder institutions (see 
Introduction). The draft guideline was reviewed by the BTS Standards of Care Committee (September 2009)

\section{REFERENCES}

1. Laennec RTH. Traité du diagnostic des maladies des poumons et du coeur. Tome Second, Paris: Brosson and Chaudé, 1819. (4)

2. Kjærgaard H. Spontaneous pneumothorax in the apparently healthy. Acta Med Scand (Suppl) 1932;43:1-159. (3)

3. Melton LJ, Hepper NCG, Offord KP. Incidence of spontaneous pneumothorax in Olmsted County, Minnesota: 1950-1974. Am Rev Respir Dis 1987;29:1379-82. (3).

4. Gupta D, Hansell A, Nichols T, et al. Epidemiology of pneumothorax in England Thorax 2000:55:666-71. (3).

5. Donahue DM, Wright CD, Viale G, et al. Resection of pulmonary blebs and pleurodesis for spontaneous pneumothorax. Chest 1993;104:1767-9. (2-)

6. Lesur 0, Delorme N, Frogamet JM, et al. Computed tomography in the aetiological assessment of idiopathic spontaneous pneumothorax. Chest 1990;98:341-7. (2+)

7. Noppen M, Dekeukeleire T, Hanon S, et al. Fluorescein-enhanced autofluorescence thoracoscopy in patients with primary spontaneous pneumothorax. Am J Respir Crit Care Med 2006;174:26-30. (3).

8. Schramel F, Meyer CJ, Postmus P. Inflammation as a cause of spontaneous pneumothorax (SP) and emphysematous like changes (ELC)? Results of bronchoalveolar lavage (BAL). Eur Respir J 1995:8(Suppl 19):397. (2-).

9. Bense L, Eklund G, Odont $D$, et al. Smoking and the increased risk of contracting pneumothorax. Chest 1987:92:1009-12. $(2++)$

10. Withers JN, Fishback ME, Kiehl PV, et al. Spontaneous pneumothorax. Am J Surg 1964;108:772-6. (3)

11. Sadikot RT, Greene T, Meadows K, et al. Recurrence of primary pneumothorax. Thorax 1997:52:805-9. (3).

12. West JB. Distribution of mechanical stress in the lung, a possible factor in localisation of pulmonary disease. Lancet 1971:1:839-41. (4).

13. Bense L, Wiman L-G, Hedenstierna G. Onset of symptoms in spontaneous pneumothorax: correlations to physical activity. Eur J Respir Dis 1987;71:181-6. (3)

14. Smit HJM, Chatrou M, Postmus PE. The impact of spontaneous pneumothorax and its treatment, on the smoking behaviour of young adult smokers. Respir Med 1998:92:1132-6. (2-)

15. Lippert HL, Lund 0 , Blegrad $\mathrm{S}$, et al. Independent risk factors for cumulative recurrence rate after first spontaneous pneumothorax. Eur Respir $J$ 1991:4:324-31. $(2+)$

16. Videm V, Pillgram-Larsen J, Ellingsen 0, et al. Spontaneous pneumothorax in chronic obstructive pulmonary disease: complications, treatment and recurrences. Eur J Respir Dis 1987:71:365-71. (2+).

17. Miller AC, Harvey JE. Guidelines for the management of spontaneous pneumothorax. BMJ 1993;307:114-16. (4)

18. Grimshaw JM, Russell IT. Effect of clinical guidelines on medical practice: a systematic review of rigorous evaluation. Lancet 1993;342:1317-21. (3).

19. Bero BA, Grilli R, Grimshaw JM, et al. Closing the gap between research and practice: an overview of systematic reviews of interventions to promote the implementation of research findings. BMJ 1998;317:465-8. (4)

20. Grilli R, Lomas J. Evaluating the message: the relationship between compliance rate and the subject of a practice guideline. Med Care 1994;32:202-13. (2+).

21. Woolf SH, Grol R, Hutchinson A, et al. Potential benefits, limitations and harms of clinical guidelines. BMJ 1999:318:527-30. (4)

22. Henry M, Arnold T, Harvey J. BTS guidelines for the management of spontaneous pneumothorax. Thorax 2003;58(Suppl II):39-52. (4).

23. Miller A. Spontaneous pneumothorax. In: Light RW, Lee YCG, eds. Textbook of pleural diseases. 2nd edn. London: Arnold Press, 2008:445-63. (4)

24. O'Hara VS. Spontaneous pneumothorax. Milit Med 1978;143:32-5. (3)

25. Pavlin J, Cheney FW Jr. Unilateral pulmonary edema in rabbits after re-expansion of collapsed lung. J Appl Physiol 1979;46:31-5. (3).

26. Miller WC, Toon $\mathrm{R}$, Palat $\mathrm{H}$, et al. Experimental pulmonary edema following reexpansion of pneumothorax. Am Rev Respir Dis 1973;108:664-6. (3).

27. Wait MA, Estrera A. Changing clinical spectrum of spontaneous pneumothorax. Am J Surg 1992:164:528-31. (2+).

28. Tanaka F, Itoh $\mathrm{M}$, Esaki $\mathrm{H}$, et al. Secondary spontaneous pneumothorax. Ann Thorac Surg 1993:55:372-6. (2-)

29. Vail WJ, Alway AE, England NJ. Spontaneous pneumothorax. Dis Chest 1960;38:512-15. (3).

30. Serementis MG. The management of spontaneous pneumothorax. Chest 1970:57:65-8. (3)

31. Norris RM, Jones JG, Bishop JM. Respiratory gas exchange in patients with spontaneous pneumothorax. Thorax 1968;23:427-33. (2+).

32. Light RW, O'Hara VS, Moritz TE, et al. Intrapleural tetracycline for the prevention of recurrent spontaneous pneumothorax: results of a Department of Veterans Affairs Co-operative Study. JAMA 1990;264:2224-30. (1+).

33. Glazer H, Anderson J, Wilson BS, et al. Pneumothorax:appearances on latera chest radiographs. Radiology 1989;173:707-11. (3).

34. Schramel FMNH, Wagenaar M, Sutedja TG, et al. Diagnosis of pneumothorax not improved by additional roentgen pictures of the thorax in the expiratory phase. Ned Tijdschr Geneeskd 1995;139:131-3. (2+).
35. Schramel FM, Golding RP, Haakman CD, et al. Expiratory chest radiographs do not improve visibility of small apical pneumothoraces by enhanced contrast. Eur Respir J 1996;9:406-9. (2+).

36. Seow A, Kazerooni EA, Cascade PN, et al. Comparison of upright inspiratory and expiratory chest radiographs for detecting pneumothoraces. AJR

1996:166:313-16. $(\mathbf{1}+)$

37. Tocino IM, Miller MH, Fairfax WR. Distribution of pneumothorax in the supine and semirecumbent critically ill adult. AJR 1985;144:901-5. (3).

38. Beres RA, Goodman LR. Pneumothorax:detection with upright versus decubitus radiography. Radiology 1993;186:19-26. $(\mathbf{2 + 1}$.

39. Warakaulle DR, Traill ZC. Imaging of pleural disease. Imaging 2004;16:10-21. (4)

40. Zhang H, Liu Z-H, Yang J-X, et al. Rapid detection of pneumothorax by ultrasonography in patients with multiple trauma. Crit Care 2006:10:R112. (2+).

41. Fajardo LL, Hillman BJ, Pond GD, et al. Detection of pneumothorax: comparison of digital and conventional chest imaging. AJR 1989:152:475-80. (2+).

42. Elam EA, Rehm K, Maloney $\mathrm{K}$, et al. Efficacy of digital radiography for the detection of pneumothorax: comparison with conventional chest radiography. AJR 1992;158:509-14. (2+)

43. Kelly A-M, Weldon D, Tsang AYL, et al. Comparison between two methods for estimating pneumothorax size from chest x-rays. Respir Med 2006;100:1356-9. (2+)

44. Phillips GD, Trotman-Dickenson B, Hodson ME, et al. Role of CT in the management of pneumothorax in patients with complex cystic lung disease. Chest 1997; 112:275-8. (3).

45. Gayer G, Rozenman J, Hoffmann C, et al. CT diagnosis of malpositioned chest tubes. Br J Radiol 2000;73:786-90. (3).

46. Engdahl 0, Toft T, Boe J. Chest radiograph-a poor method for determining the size of a pneumothorax. Chest 1993:103:26-9. (3).

47. Flint K, Al-Hillawi AH, Johnson NM. Conservative management of spontaneous pneumothorax. Lancet 1984;ii:687-8. (3).

48. Kircher LT Jr, Swartzel RL. Spontaneous pneumothorax and its treatment. JAMA 1954;155:24-9. (3)

49. Baumann MH, Strange C, Heffner JE, et al. Management of spontaneous pneumothorax. An American College of Chest Physicians Delphi Consensus statement. Chest 2001;119:590-602. (1-)

50. Kelly AM, Druda D. Comparison of size classification of primary spontaneous pneumothorax by three international guidelines: a case for international consensus? Respir Med 2008;102:1830-2. (2+).

51. Hoi K, Turchin B, Kelly AM. How accurate is the light index for estimating pneumothorax size? Austral Radiol 2007;51:196-8. (2+).

52. Kelly AM, Loy J, Tsang AYL, et al. Estimating the rate of re-expansion of spontaneous pneumothorax by a formula derived from computed tomography volumetry studies. Emerg Med J 2006;23:780-2. (2+)

53. Stradling $\mathbf{P}$, Poole G. Conservative management of spontaneous pneumothorax. Thorax 1966:21:145-9. (3)

54. Hart GJ, Stokes TC, Couch AHC. Spontaneous pneumothorax in Norfolk. Br J Dis Chest 1983:77:164-70. (3)

55. O'Rourke JP, Yee ES. Civilian spontaneous pneumothorax: treatment options and long term results. Chest 1989;96:1302-6. (3).

56. Chadha TS, Cohn MA. Noninvasive treatment of pneumothorax with oxygen inhalation. Respiration 1983;44:147-52. (3).

57. Northfield TC. Oxygen therapy for spontaneous pneumothorax BMJ 1971:4:86-8. (2-).

58. Light RW, Lee YCG. Pneumothorax, chylothorax, hemothorax and fibrothorax. In: Murray J, Nadel J, Mason R, et al, eds. Textbook of respiratory diseases. 5th edn Philadelphia: Saunders Elsevier, 2010:1764-91. (4)

59. Noppen M, Alexander P, Driesen P, et al. Manual aspiration versus chest tube drainage in first episodes of primary spontaneous pneumothorax. Am J Respir Crit Care Med 2002;165:1240-4. (1+).

60. Harvey J, Prescott RJ. Simple aspiration versus intercostal tube drainage for spontaneous pneumothorax in patients with normal lungs. BMJ 1994;309:1338-9. (1-).

61. Andrivert P, Djedaim K, Teboul JL, et al. Spontaneous pneumothorax: comparison of thoracic drainage vs immediate or delayed needle aspiration. Chest 1995; 108:335-40. (1-)

62. Ayed AK, Chandrasekaran C, Sukumar M, et al. Aspiration versus tube drainage in primary spontaneous pneumothorax: a randomised study. Eur Respir $J$ 2006;27:477-82. (1+).

63. Masood I, Ahmad Z, Pandey DK, et al. Role of simple needle aspiration in the management of spontaneous pneumothorax. J Assoc Phys Ind 2007; 55:628-9. (1-).

64. Camuset $\mathbf{J}$, Laganier $\mathbf{J}$, Brugiere 0 , et al. Needle aspiration as first-line management of primary spontaneous pneumothorax. Presse Med 2006;35:765-8. (3).

65. Chan SSW, Lam PKW. Simple aspiration as initial treatment for primary spontaneous pneumothorax: results of 91 consecutive cases. J Emerg Med 2005; 28:133-8. (3)

66. Devanand A, Koh MS, Ong TH, et al. Simple aspiration versus chest-tube insertion in the management of primary spontaneous pneumothorax: a systematic review (provisional record). Respir Med 2004;98:579-90. (1+)

67. Zehtabchi S, Rios CL. Management of emergency department patients with primary spontaneous pneumothorax: needle aspiration or tube thoracostomy? Ann Emerg Med 2008;51:91-100. (1+). 
68. Wakai A, O'Sullivan RG, McCabe G. Simple aspiration versus intercostal tube drainage for primary spontaneous pneumothorax in adults. Cochrane Database Syst Rev 2007;(1):CD 004479. (1+).

69. Archer GJ, Hamilton AA, Upadhyay $R$, et al. Results of simple aspiration of pneumothoraces. Br J Dis Chest 1985;79:177-82. (3).

70. Markos J, McGonigle P, Phillips MJ. Pneumothorax: treatment by small-lumen catheter aspiration. Aust NZ Med 1990;20:775-81. (3).

71. Bevelaqua FA, Aranda C. Management of spontaneous pneumothorax with small lumen catheter manual aspiration. Chest 1982:81:693-4. (3).

72. Seaton D, Yoganathan K, Coady T, et al. Spontaneous pneumothorax: marker gas technique for predicting outcome of manual aspiration. BMJ 1991;302:697. (3)

73. $\mathbf{N g ~ A W , ~ C h a n ~ K W , ~ L e e ~ S K . ~ S i m p l e ~ a s p i r a t i o n ~ o f ~ p n e u m o t h o r a x . ~ S i n g a p o r e ~ M e d ~ J ~}$ 1994;35:50-2. (3)

74. Raja OG, Lalor AJ. Simple aspiration of spontaneous pneumothorax. Br J Dis Chest 1981:75:207-8. (3)

75. Jones JS. A place for aspiration in the treatment of spontaneous pneumothorax Thorax 1985:40:66-7. (3)

76. Talbot-Stern J, Richardson H, Tomlanovich MC, et al. Catheter aspiration for simple pneumothorax. J Emerg Med 1986;4:437-42. (3).

77. Chan SS. The role of simple aspiration in the management of primary spontaneous pneumothorax. J Emerg Med 2008;34:131-8. (3).

78. Soulsby T. British Thoracic Society guidelines for the management of spontaneous pneumothorax: do we comply with them and do they work? J Accid Emerg Med 1998;15:317-21. (3)

79. Yeoh JH, Ansari S, Campbell IA. Management of spontaneous pneumothorax-a Welsh survey. Postgrad Med J 2000;76:496-500. (3).

80. Mendis D, El-Shanawany T, Mathur A, et al. Management of spontaneous pneumothorax: are British Thoracic Society guidelines being followed? Postgrad Med J 2002;87:80-4. (3)

81. Packham S, Jaiswal P. Spontaneous pneumothorax: use of aspiration and outcomes of management by respiratory and general physicians. Postgrad Med $\mathrm{J}$ 2003; 79:345-7. (3)

82. Medford ARL, Pepperell CT. Management of spontaneous pneumothorax compared to British Thoracic Society (BTS) 2003 guidelines: a district general hospital audit. Prim Care Respir J 2007;16:291-8. (3).

83. Reinhold C, Illescas FF, Atri M, et al. Treatment of pleural effusions and pneumothorax with catheters placed percutaneously under imaging guidance. AJR 1989;152:1189-91. (3).

84. Conces DJ Jr, Tarver RD, Gray WC, et al. Treatment of pneumothoraces utilizing small calibre chest tubes. Chest 1988;94:55-7. (3)

85. Minami H, Saka H, Senda K, et al. Small calibre catheter drainage for spontaneous pneumothorax. Am J Med Sci 1992:304:345-7. (3).

86. Campisi P, Voitk AJ. Outpatient treatment of spontaneous pneumothorax in a community hospital using a Heimlich flutter valve: a case series. J Emerg Med 1997:15:115-19. (3)

87. Dernevik L, Roberts D, Hamraz B, et al. Management of pneumothorax with a mini-drain in ambulatory and hospitalized patients. Scand Cardiovasc J 2003;37:172-6. (3).

88. Horsley A, Jones L, White J, et al. Efficacy and complications of small-bore, wireguided chest drains. Chest 2006;130:1857-63. (3).

89. Funaki B. Pneumothorax treated by small-bore chest tube. Semin Intervent Radiol 2007:24:272-6. (3)

90. Vedam H, Barnes DJ. Comparison of large- and small-bore intercostal catheters in the management of spontaneous pneumothorax. Int Med J 2003;33:495-9. (3).

91. Clementsen $\mathbf{P}$, Evald T, Grode G, et al. Treatment of malignant pleural effusion: pleurodesis using a small percutaneous catheter. A prospective randomized study. Respir Med 1998;92:593-6. (2+).

92. Akowuah E, Ho EC, George R, et al. Less pain with flexible fluted silicone chest drains than with conventional rigid chest tubes after cardiac surgery. $J$ Thorac Cardiovasc Surg 2002;124:1027-8. (2+)

93. Vallee $\mathbf{P}$, Sullivan $\mathrm{M}$, Richardson $\mathrm{H}$, et al Sequential treatment of a simple pneumothorax. Ann Emerg Med 1988;17:936-47. (3)

94. Delius RE, Obeid FN, Horst HM, et al. Catheter aspiration for simple pneumothorax. Arch Surg 1989:124:833-6. (3).

95. Laub M, Milman N, Muller D. Role of small calibre chest tube drainage for iatrogenic pneumothorax. Thorax 1990;45:748-9. (3).

96. Marquette $\mathbf{C H}$, Marx A, Leroy $\mathrm{S}$, et al. Simplified stepwise management of primary spontaneous pneumothorax: a pilot study. Eur Respir J 2006;27:470-6. (3)

97. De Leyn $\mathbf{P}$, Lismonde M, Ninane V, et al. Belgian Society of Pneumology. Guidelines on the management of spontaneous pneumothorax. Acta Chir Belg 2005; 105:265-7. (1+)

98. Chen JS, Hsu HH, Tsai KT, et al. Salvage for unsuccessful aspiration of primary pneumothorax: thoracoscopic surgery or chest tube drainage? Ann Thorac Surg 2008:85:1908-13. (3)

99. So SY, Yu DY. Catheter drainage of spontaneous pneumothorax: suction or no suction, early or late removal? Thorax 1982;37:46-8. (1-)

100. Sharma TN, Agrihotri SP, Jain NK, et al. Intercostal tube thoracostomy in pneumothorax: factors influencing re-expansion of lung. Ind J Chest Dis All Sci 1988; 30:32-5. (1-)

101. Reed MF, Lyons JM, Luchette FA, et al. Preliminary report of a prospective, randomized trial of underwater seal for spontaneous and iatrogenic pneumothorax. J Am Coll Surg 2007;204:84-90. (3).
102. Mathur R, Cullen J, Kinnear WJM, et al. Time course of resolution of persistent air leak in spontaneous pneumothorax. Respir Med 1995;89:129-32. (3)

103. Munnell ER. Thoracic drainage. Ann Thorac Surg 1997;63:1497-502. (4).

104. Pierson DJ. Persistent bronchopleural air-leak during mechanical ventilation: a review. Respir Care 1982;27:408-15. (4).

105. Harriss DR, Graham TR. Management of intercostal drains. Br J Hosp Med 1991:45:383-6. (4)

106. Matsuura Y, Nomimura T, Nurikami $H$, et al. Clinical evidence of re-expansion pulmonary edema. Chest 1991:100:1562-6. (3).

107. Pavlin DJ, Nessly MC, Cheney FW. Increased pulmonary vascular permeability as a cause of re-expansion edema in rabbits. Am Rev Respir Dis 1981;124:422-7. (3)

108. Mahfood S, Hix WR, Aaron BL, et al. Re-expansion pulmonary edema. Ann Thorac Surg 1988; 45:340-5. (3)

109. Maunder RJ, Pierson DJ, Hudson LD. Subcutaneous and mediastinal emphysema Pathophysiology, diagnosis and management. Arch Intern Med 1984;144:1447-53. (3).

110. Conetta R, Barman AA, Lakovou $C$, et al. Acute ventilatory failure from massive subcutaneous emphysema. Chest 1993;104:978-80. (3).

111. Chee CBE, Abisheganaden J, Yeo JKS, et al. Persistent air-leak in spontaneous pneumothorax — clinical course and outcome. Respir Med 1998:92:757-61. (3).

112. Schoenenberger RA, Haefeli WE, Weiss $P$, et al. Timing of invasive procedures in therapy for primary and secondary spontaneous pneumothorax. Arch Surg 1991:126:764-6. (3).

113. British Thoracic Society Emergency Oxygen Guideline Group. Guideline for emergency oxygen use in adult patients. Thorax 2008;63(Suppl V1):1-68. (4).

114. Tsai WK, Chen W, Lee JC, et al. Pigtail catheters vs large-bore chest tubes for the management of secondary spontaneous pneumothoraces in adults. Am J Emerg Med 2006:24:795-800. (2-).

115. Waller DA, McConnell SA, Rajesh PB. Delayed referral reduces the success of video-assisted thoracoscopic surgery for spontaneous pneumothorax. Respir Med 1998:92:246-9. (3)

116. British Thoracic Society Standards of Care Committee. Managing passengers with respiratory disease planning air travel: British Thoracic Society recommendations. Thorax 2002:57:289-304. (4)

117. Ziser A, Vaananen A, Melamed Y. Diving and chronic spontaneous pneumothorax Chest 1985:87:264-5. (3)

118. British Thoracic Society Fitness to Dive Group. BTS guidelines on respiratory aspects of fitness for diving. Thorax 2003;58:3-11. (4).

119. Almind M, Lange P, Viskum K. Spontaneous pneumothorax: comparison of simple drainage, talc pleurodesis and tetracycline pleurodesis. Thorax 1989; 44:627-30. (1+)

120. Olsen PS, Anderson HO. Long term results after tetracycline pleurodesis in spontaneous pneumothorax. Ann Thorac Surg 1992;53:1015-17. (3).

121. Massard G, Thomas P, Wihlm J-M. Minimally invasive management for first and recurrent pneumothorax. Ann Thorac Surg 1998:66:592-9. (4).

122. Torre $\mathbf{M}$, Grassi $\mathbf{M}$, Nerli FP, et al. Nd-Yag laser pleurodesis via thoracoscopy. Chest 1994:106:338-41. (3).

123. Vargas FS, Wang N-S, Lee HM, et al. Effectiveness of bleomycin in comparison to tetracycline as pleural sclerosing agents in rabbits. Chest 1993;104:1582-4. $(2+)$

124. Van den Brande $\mathbf{P}$, Staelans I. Chemical pleurodesis in primary spontaneous pneumothorax. J Thorac Cardiovasc Surg 1989;37:180-2. (1-).

125. Alfegeme I, Moreno L, Heurtas C, et al. Spontaneous pneumothorax: long term results with tetracycline pleurodesis. Chest 1994;106:347-50. (2+).

126. Light RW, Wang N-S, Sassoon CS, et al. Comparison of the effectiveness of tetracycline and minocycline as pleural sclerosing agents in rabbits. Chest 1994; 106:577-82. (2+).

127. Hurewitz AN, Lidonicci K, Wu CL, et al. Histologic changes of doxycycline pleurodesis in rabbits. Chest 1994;106:1241-5. (2+)

128. Barker A, Maratos EC, Edmonds $L$, et al. Recurrence rates of video-assisted thoracoscopic versus open surgery in the prevention of recurrent pneumothorax: a systematic review of randomised and non-randomised trials. Lancet 2007; 370:329-35. $(\mathbf{1}++)$

129. Vohra HA, Adamson L, Weeden DF. Does video-assisted thoracoscopic pleurectomy result in better outcomes than open pleurectomy for primary spontaneous pneumothorax? Int Cardiovasc Thorac Surg 2008;7:673-7. $(\mathbf{1 + + )}$

130. Schramel FM, Postmus PE, Vanderschueren RG. Current aspects of spontaneous pneumothorax. Eur Respir J 1997;10:1372-9. (4)

131. Hatz RA, Kaps MF, Meimarakis G, et al. Long-term results after video-assisted thoracoscopic surgery for first-time and recurrent spontaneous pneumothorax. Ann Thorac Surg 2000;70:253-7. (3).

132. Noppen $\mathbf{M}$, Meysman $\mathbf{M}$, d'Haese $\mathrm{J}$, et al. Comparison of video-assisted thoracoscopic talcage for primary versus persistent secondary spontaneous pneumothorax. Eur Respir J 1997:10:412-16. (3)

133. Cardillo G, Carleo F, Giunti R, et al. Videothorascopic talc poudrage in primary spontaneous pneumothorax: a single-institution experience in 861 cases. $J$ Thorac Cardiovasc Surg 2006;131:322-8. (3).

134. Wang YT, Ng KY, Poh SC. Intrapleural tetracycline for spontaneous pneumothorax with persistent air leak. Singapore Med J 1988;29:72-3. (3)

135. Macoviak JA, Stephenson LW, Ochs R, et al. Tetracycline pleurodesis during active pulmonary-pleural air leak for prevention of recurrent pneumothorax. Chest 1982; 81:78-81. $(\mathbf{1}+)$ 
136. Sherman S, Ravikrishnan KP, Patel A, et al. Optimum anaesthesia with intrapleural lidocaine during chemical pleurodesis with tetracycline. Chest 1993;3:533-6. $(2-)$

137. Thevenet F, Gamondes JP, Bodzongo D, et al. Spontaneous and recurrent pneumothorax. Surgical review of 278 cases. Ann Chir 1992;46:165-9. (3).

138. Weedon D, Smith GH. Surgical experience in the management of spontaneous pneumothorax, 1972-1982. Thorax 1983;38:737-43. (3)

139. Körner H, Anderson KS, Strangeland L, et al. Surgical treatment of spontaneous pneumothorax by wedge resection without pleurodesis or pleurectomy. Eur $\mathrm{J}$ Cardiothorac Surg 1996;10:656-9. (3).

140. Thomas $\mathbf{P}$, Le Mee F, Le Hars $\mathrm{H}$, et al. Results of surgical treatment of persistent or recurrent pneumothorax. Ann Chir 1993:47:136-40. (3).

141. Granke K, Fischer CR, Gago 0, et al. The efficacy and timing of operative intervention for spontaneous pneumothorax. Ann Thorac Surg 1986:42:540-2. (2-)

142. Shah SS, Cohen AS, Magee PG, et al. Surgery remains a late and under-utilised option in the management of spontaneous pneumothorax: should the British Thoracic Society guidelines be revisited? Thorax 1998:53(Suppl 4):A52. (3)

143. Luh SP, Tsao TCY. Video-assisted thoracic surgery for spontaneous haemopneumothorax. Respirology 2007;12:443-7. (3).

144. Hwong TMT, $\mathrm{Ng} \mathrm{CSH}$, Lee TW, et al. Video-assisted thoracic surgery for primary spontaneous haemopneumothorax. Eur J Cardio-Thorac Surg 2004;26:893-6. (3).

145. Inderbitzi RG, Leiser A, Furrer M, et al. Three years experience in video-assisted thoracic surgery (VATS) for spontaneous pneumothorax. J Thorac Cardiovasc Surg 1994; 107:1410-15. (3)

146. Cran IR, Rumball CA. Survey of spontaneous pneumothorax in the Royal Air Force. Thorax 1967:22:462-5. (3).

147. Parry GN, Juniper ME, Dussek JE. Surgical intervention in spontaneous pneumothorax. Respir Med 1992;86:1-2. (4).

148. Chou SH, Cheng YJ, Kao EL. Is video-assisted thoracic surgery indicated in the first episode primary spontaneous pneumothorax? Int Cardiovasc Thorac Surg 2003:2:552-4. (3)

149. Pompeo E, Tacconi F, Mineo D, et al. The role of awake video-assisted thoracoscopic surgery in spontaneous pneumothorax. J Thorac Cardiovasc Surg 2007:133:786-90. $(1+)$.

150. Passlick B, Born C, Sienel W, et al. Incidence of chronic pain after minimal-invasive surgery for spontaneous pneumothorax. Eur J Cardio-Thorac Surg 2001:19:355-8. (3)

151. Sihoe ADL, Au SSW, Cheung ML, et al. Incidence of chest wall paresthesia after video-assisted thoracic surgery for primary spontaneous pneumothorax. Eur $\mathrm{J}$ Cardio-Thorac Surg 2004;25:1054-8. (3).

152. Morimoto T, Shimbo T, Noguchi Y, et al. Effects of timing of thoracoscopic surgery for primary spontaneous pneumothorax on prognosis and costs. Am J Surg 2004;187:767-74. (3).

153. Gaensler EA. Parietal pleurectomy for recurrent spontaneous pneumothorax. Surg Gynecol Obstet 1956;102:293-308. (3, 4).

154. Claggett OT. The management of spontaneous pneumothorax. J Thorac Cardiovasc Surg 1968;55:761-2. (4)

155. Cheynel N, Bernard A, Belichard C, et al. Comparative study of thoracoscopy and thoracotomy in spontaneous pneumothorax. Lyon Chir 1994;90:193-6. (2-)

156. Elfeldt RJ, Schroder DW, Thies J. Long term follow-up of different therapy procedures in spontaneous pneumothorax. J Cardiovasc Surg Torino 1994;35:229-33. (2-).

157. Gilliland R, McGuigan JA, McManus KG. Thoracoscopic management of primary spontaneous pneumothorax - a comparative study. Min Invas Ther Allied Technol 1996;5:69-74. (2-).

158. Ingolfssen I, Gyllstedt E, Lillo-Gil R, et al. Reoperations are common following VATS for spontaneous pneumothorax: study of risk factors. Interact Cardiovasc Thorac Surg 2006;5:602-7. (3).

159. Tyson MD, Crandall WB. The surgical treatment of recurrent idiopathic spontaneous pneumothorax. J Thorac Surg 1941;10:566-70. (3)

160. Deslauriers J, Beaulieu M, Despres JP, et al. Transaxillary pleurectomy for treatment of spontaneous pneumothorax. Ann Thorac Surg 1980:30:567-74. (3)

161. Becker RM, Munro DD. Transaxillary minithoracotomy: the optimal approach for certain pulmonary and mediastinal lesions. Ann Thorac Surg 1976;22:254-9. (3)

162. Waller DA, Forty J, Morritt GN. Video-assisted thoracoscopic surgery versus thoracotomy for spontaneous pneumothorax. Ann Thorac Surg 1994; 58:373-7. (1+)

163. Waller DA. Video-assisted thoracoscopic surgery (VATS) in the management of spontaneous pneumothorax. Thorax 1997;52:307-8. (4).

164. Naunheim KS, Mack MJ, Hazelrigg SR, et al. Safety and efficacy of video-assisted thoracic surgical techniques for the treatment of spontaneous pneumothorax. J Thorac Cardiovasc Surg 1995;109:1198-204. (3)

165. Horio H, Nomori $\mathrm{H}$, Fuyuno $\mathrm{G}$, et al. Limited axillary thoracotomy vs video-assisted thoracoscopic surgery for spontaneous pneumothorax. Surg Endosc 1998;12:1155-8. (3).

166. Al-Tarshihi M. Comparison of the efficacy and safety of video-assisted thoracoscopic surgery with the open method for the treatment of primary spontaneous pneumothorax. Ann Thorac Med 2008;3:9-12. (2-)

167. Sedrakyan A, van der Meulen J, Lewsey J, et al. Video assisted thoracic surgery for treatment of pneumothorax and lung resections: systematic review of randomised clinical trials. BMJ 2004;329:1008-10. (1+).

168. Sawada S, Watanabe Y, Moriyama S. Video-assisted thoracoscopic surgery for primary spontaneous pneumothorax: evaluation of indications and long-term outcome compared with conservative treatment and open thoracotomy. Chest 2005;127:2226-30. (3).

169. Freixinet JL, Canalis E, Julia G, et al. Axillary thoracotomy versus videothoracoscopy for the treatment of primary spontaneous pneumothorax. Ann Thorac Surg 2004;78:417-20. (1+)

170. Van Schil P. Cost analysis of video-assisted thoracic surgery versus thoracotomy: critical review. Eur Respir J 2003;22:735-8. (1++).

171. Dumont P, Diemont F, Massard G, et al. Does a thoracoscopic approach for surgical treatment of spontaneous pneumothorax represent progress? Eur $\mathrm{J}$ CardioThorac Surg 1997;11:22-31. (3).

172. Mouroux J, Elkaim D, Padavoni B, et al. Video-assisted thoracoscopic treatment of spontaneous pneumothorax: technique and results of one hundred cases. J Thorac Cardiovasc Surg 1996;112:385-91. (3).

173. Bertrand PC, Regnard JP, Spaggiari L, et al. Immediate and long term results afte surgical treatment of primary spontaneous pneumothorax by VATS. Ann Thorac Surg 1996;61:1641-5. (3).

174. Gebhard FT, Becker HP, Gerngross $H$, et al. Reduced inflammatory response in minimally invasive surgery of pneumothorax. Arch Surg 1996;131:1079-82. (1-)

175. Cole FH Jr, Cole FH, Khandekar A, et al. Video-assisted thoracic surgery: primary therapy for spontaneous pneumothorax? Ann Thorac Surg 1995:60:931-5. (2-).

176. Sekine Y, Miyata Y, Yamada H, et al. Video-assisted thoracoscopic surgery does not deteriorate postoperative pulmonary gas exchange in spontaneous pneumothorax patients. Eur J Cardiothorac Surg 1999;16:48-53. (1+).

177. Kim KH, Kim HK, Han JY, et al. Transaxillary minithoracotomy versus video-assisted thoracic surgery for spontaneous pneumothorax. Ann Thorac Surg 1996;61:1510-12. $(\mathbf{1}+)$

178. Kennedy L, Sahn SA. Talc pleurodesis for the treatment of pneumothorax and pleural effusion. Chest 1994:106:1215-22. (2)

179. Tschopp JM, Brutsche M, Frey JG. Treatment of complicated pneumothorax by simple talc pleurodesis under thoracoscopy and local anaesthesia. Thorax 1997:52:329-32. (3).

180. Lee $\mathbf{P}$, Yap W, Pek W, et al. An audit of medical thoracoscopy and talc poudrage for pneumothorax prevention in advanced COPD. Chest 2004;125:1315-20. (3).

181. Rinaldo JE, Owens GR, Roger RM. Adult respiratory distress syndrome following intrapleural instillation of talc. J Thorac Cardiovasc Surg 1983;85:523-6. (4)

182. Maskell NA, Lee YC, Gleeson FV, et al. Randomized trials describing lung inflammation after pleurodesis with talc of varying particle size. Am J Respir Crit Care Med 2004;170:377-82. (1+).

183. Janssen JP, Collier G, Astoul P, et al. Safety of pleurodesis with talc poudrage in malignant pleural effusion: a prospective cohort study. Lancet 2007;369:1535-9. $(2++)$.

184. Kennedy L, Rusch VW, Strange C, et al. Pleurodesis using talc slurry Chest 1994;106:342-6. (3).

185. Hamed H, Fentiman IS, Chaudary MA, et al. Comparison of bleomycin and talc for the control of pleural effusions secondary to carcinoma of the breast. $\mathrm{Br} J$ Surg 1989;76:1266-7. (1-)

186. Light RW. Tension pneumothorax. Intensive Care Med 1994;20:468-9. (4).

187. Baumann MH, Sahn SA. Tension pneumothorax: diagnostic and therapeutic pitfalls. Crit Care Med 1993;21:177-9. (4)

188. Leigh-Smith S, Harris T. Tension pneumothorax - time for a re-think? Emerg Med J 2005;22:8-16. (4)

189. Marinaro JL, Kenny CV, Smith SR, et al. Needle thoracostomy in trauma patients: what catheter length is adequate? Acad Emerg Med 2003;10:495. (3)

190. Terndrup TE, Bosco SF, McLean ER. Spontaneous pneumothorax complicating pregnancy: case report and review of the literature. J Emerg Med 1989;7:245-8. (3)

191. Lal A, Anderson G, Cowen M, et al. Pneumothorax and pregnancy. Chest 2007;132:1044-8. (3)

192. Korom S, Canyurt H, Missbach A, et al. Catamenial pneumothorax revisited: clinical approach and systematic review of the literature. J Thorac Cardiovasc Surg 2004; 128:502-8. (3).

193. Alifano M, Roth T, Broet SC, et al. Catamenial pneumothorax: a prospective study Chest 2003;124:1004-8. (3).

194. Alifano M, Jablonski C, Kadiri H, et al. Catamenial and noncatamenial, endometriosis-related or nonendometriosis-related pneumothorax referred for surgery. Am J Respir Crit Care Med 2007:176:1048-53. (3).

195. Leong AC, Coonar AS, Lang-Lazdunski L. Catamenial pneumothorax: surgical repai of the diaphragm and hormone treatment. Ann R Coll Surg 2006;88:547-9. (3).

196. Sepkowitz KA, Telzac EE, Gold JWM, et al. Pneumothorax in AIDS. Ann Intern Med 1991:114:455-9. (2+).

197. Gerein AN, Brumwell ML, Lawson LM, et al. Surgical management of pneumothorax in patients with acquired immune deficiency syndrome. Arch Surg 1991:126:1272-7. (3)

198. Delorenzo LT, Huang CT, Maguire GP, et al. Roentgenographic patterns of Pneumocystis carinii in 104 patients with AIDS. Chest 1987;91:323-7. (3)

199. Light RW, Hamm H. Pleural disease and acquired immune deficiency syndrome. Eur Respir J 1997;10:2638-43. (4).

200. Suster B, Akerman M, Orenstein M, et al. Pulmonary manifestations of AIDS: review of 106 episodes. Radiology 1986;161:87-93. (3)

201. Eng RHK, Bishburg E, Smith SM. Evidence for destruction of lung tissue during Pneumocystis carinii infection. Arch Intern Med 1987;147:746-9. (3).

202. Metersky ML, Colt HG, Olson LK, et al. AIDS-related spontaneous pneumothorax Risk factors and treatment. Chest 1995;108:946-51. (2+). 
203. Wait MA, Dal Nogare AR. Treatment of AIDS-related spontaneous pneumothorax: a decade of experience. Chest 1994;106:693-6. (3)

204. Coker RJ, Moss F, Peters B, et al. Pneumothorax in patients with AIDS. Respir Med 1993;87:43-7. (3).

205. Asboe D, Fisher M, Nelson MR, et al. Pneumothorax in AIDS: case reviews and proposed clinical management. Genitourin Med 1996:72:258-60. (3).

206. Mahungu TW, Rodger AJ, Johnson MA. HIV as a chronic disease. Clin Med 2009; $9: 125-8$. (4)

207. Morris A, Wachter RM, Luce J, et al. Improved survival with highly active antiretroviral therapy in HIV-infected patients with severe Pneumocystis carinii pneumonia. AIDS 2003;17:73-80. (2+).

208. Flume PA, Strange $C, Y e X$, et al. Pneumothorax in cystic fibrosis. Chest 2005;128:720-8. $(\mathbf{2 + +}$.

209. Spector ML, Stern SC. Pneumothorax in cystic fibrosis: a 26-year experience. Ann Thorac Surg 1989;47:204-7. (3).

210. Tribble CG, Selden RF, Rodgers BM. Talc poudrage in the treatment of spontaneous pneumothoraces in patients with cystic fibrosis. Ann Surg 1986;204:677-80. (3).

211. Davis PB, di Sant'Agnese PA. Diagnosis and treatment of cystic fibrosis: an update. Chest 1984:85:802-9. (4).

212. Schuster SR, McLaughlin FJ, Matthews WJ, et al. Management of pneumothorax in cystic fibrosis. J Pediatr Surg 1983;18:492-7. (3).

213. Penketh ARL, Knight RK, Hodson ME, et al. Management of pneumothorax in adults with cystic fibrosis. Thorax 1982;37:850-3. (3).
214. Noyes BE, Orenstein DM. Treatment of pneumothorax in cystic fibrosis in the era of lung transplantation. Chest 1992;101:1187-8. (4).

215. Curtis HJ, Bourke SJ, Dark JH, et al. Lung transplantation outcome in cystic fibrosis patients with previous pneumothorax. J Heart Lung Transplant 2005;24:865-9. (3)

216. Sassoon CSH, Light RW, O'Hara VS, et al. latrogenic pneumothorax: etiology and morbidity. Respiration 1992;59:215-20. (3).

217. Despars JA, Sassoon CSH, Light RW. Significance of iatrogenic pneumothoraces Chest 1994:105:1147-50. (3).

218. Britten S, Palmer SH, Snow TM. Needle thoracocentesis in tension pneumothorax: insufficient cannula length and potential failure. Injury 1996;27:321-2. (3).

219. Poe RH, Kallay MC, Wicks CM, et al. Predicting risk of pneumothorax in needle biopsy of the lung. Chest 1984;85:232-5. (3).

220. Zhan C, Smith M, Stryer D. Accidental iatrogenic pneumothorax in hospitalized patients. Med Care 2006:44:182-6. (3).

221. Berger $\mathbf{R}$, Smith D. Efficacy of the lateral decubitus position in preventing pneumothorax after needle biopsy of the lung. South Med J 1988:81:1140-3. (2+).

222. Anderson CLV, Crespo JCA, Lie TH. Risk of pneumothorax not increased by obstructive lung disease in percutaneous needle biopsy. Chest 1994:105:1705-8. (3)

223. de Lassence $\mathbf{A}$, Timsit J-F, Tafflet $\mathrm{M}$, et al. Pneumothorax in the intensive care unit: incidence, risk factors, and outcome. Anesthesiology 2006;104:5-13. (2++).

224. Pollack MM, Fields Al, Holbrook PR. Pneumothorax and pneumomediastinum during pediatric mechanical ventilation. Crit Care Med 1979;7:536-9. (3). 